\title{
SIRT1 and SIRT6 Signaling Pathways in Cardiovascular Disease Protection
}

\author{
Nunzia D'Onofrio, Luigi Servillo, and Maria Luisa Balestrieri
}

\begin{abstract}
Significance: Oxidative stress represents the common hallmark of pathological conditions associated with cardiovascular disease (CVD), including atherosclerosis, heart failure, hypertension, aging, diabetes, and other vascular system-related diseases. The sirtuin (SIRT) family, comprising seven proteins (SIRT1-SIRT7) sharing a highly conserved nicotinamide adenine dinucleotide $\left(\mathrm{NAD}^{+}\right)$-binding catalytic domain, attracted a great attention for the past few years as stress adaptor and epigenetic enzymes involved in the cellular events controlling aging-related disorder, cancer, and CVD.

Recent Advances: Among sirtuins, SIRT1 and SIRT6 are the best characterized for their protective roles against inflammation, vascular aging, heart disease, and atherosclerotic plaque development. This latest role has been only recently unveiled for SIRT6. Of interest, in recent years, complex signaling networks controlled by SIRT1 and SIRT6 common to stress resistance, vascular aging, and CVD have emerged.

Critical Issues: We provide a comprehensive overview of recent developments on the molecular signaling pathways controlled by SIRT1 and SIRT6, two post-translational modifiers proven to be valuable tools to dampen inflammation and oxidative stress at the cardiovascular level.

Future Directions: A deeper understanding of the epigenetic mechanisms through which SIRT1 and SIRT6 act in the signalings responsible for onset and development CVD is a prime scientific endeavor of the upcoming years. Multiple "omic" technologies will have widespread implications in understanding such mechanisms, speeding up the achievement of selective and efficient pharmacological modulation of sirtuins for future applications in the prevention and treatment of CVD. Antioxid. Redox Signal. 28, 711-732.
\end{abstract}

Keywords: SIRT1, SIRT6, oxidative stress, endothelial dysfunction, vascular aging, cardiovascular disease

\section{Introduction}

Q IRTUins (SIRT), NiCOTINAMIDE ADENINE DINUCLEOTIDE $\boldsymbol{N}\left(\mathrm{NAD}^{+}\right)$-dependent deacetylating enzymes firstly identified in the yeast, belong to the class III histone deacetylases (62). They share a highly conserved $\mathrm{NAD}^{+}$-binding catalytic domain with $\sim 250$ amino acid core and variable amino- and carboxy-terminal extensions.

Mammals possess seven sirtuins with different terminal extensions determining their various subcellular localization, enzymatic activity, and binding targets (22). SIRT1 is localized in the nucleus and translocates to the cytosol under specific conditions $(22,42,169)$. Similarly, based on some evidence, it appears that SIRT6 is also localized in the cy- tosol, rather than exclusively in nucleus. Indeed, SIRT6 has been demonstrated to localize to cytoplasmic stress granules in response to stress $(42,80,159)$. SIRT2 resides predominantly in the cytosol, SIRT3, SIRT4, and SIRT5 are mitochondrial, and SIRT7 is nuclear and nucleolar. Besides the well-recognized deacetylase function, sirtuins have also evolved as mono-ADP-ribosyltransferase, lipoamidase (SIRT4), hydrolase (SIRT6), demalonylase, decrotonylase (SIRT3) (18), and desuccinylase (SIRT5) (62, 72) (Fig. 1).

Sirtuins regulate essential molecular pathways in eubacteria, archaea, and eukaryotes and are established longevity factors involved in the beneficial effects of caloric restriction. Thanks to their chromatin-modifying activity, sirtuins account for global transcriptional changes generally 


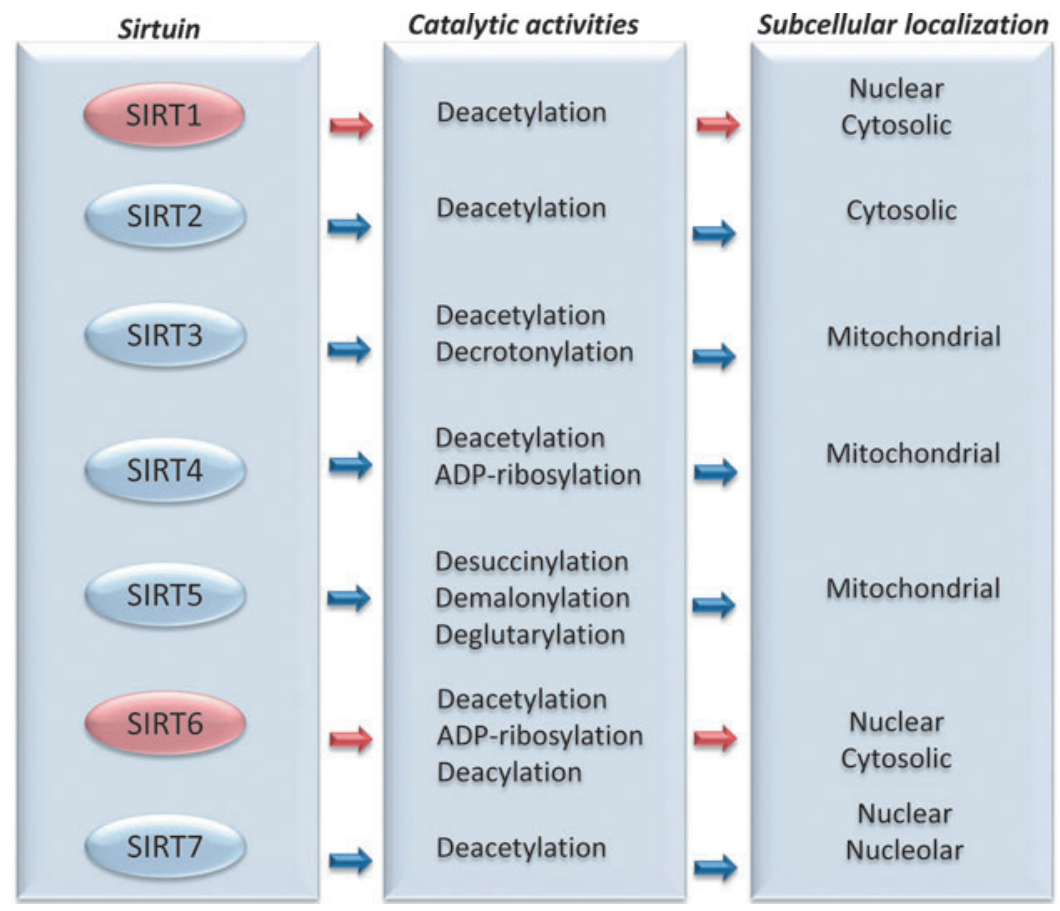

FIG. 1. Mammalian sirtuins. Schematic representation of the seven members of sirtuin family with their catalytic activity and predominant subcellular localization. associated with variation in energy metabolism, aging, and oxidative stress resistance. Indeed, they are involved in a plethora of metabolic and homeostatic processes, including gluconeogenesis, fatty acid oxidation, oxidative phosphorylation, urea cycle, and endothelium homeostasis (42, 185). Sirtuins display a degree of redundancy and partially overlapping functions as a consequence of cell adaptation to regulate more than one cellular compartment compared with prokaryotic cells. Indeed, in mammals, SIRT1 and SIRT2 regulate c-Myc by increasing its stability and enhancing activation of its transcription targets $(50,117)$.

Accumulating evidence indicates that sirtuins, by performing a crucial role in cell plasticity mechanisms of adaptation to nutrient stresses, are not only important sensors of the energy status but also counteract cell metabolic stresses, thus attracting a tremendous attention for the past few years as stress adaptors (88). Central is their role in age-associated metabolic disorders, as well as in stress tolerance. Indeed, they are implicated in the responses to hypoxic, heat shock or genotoxic stresses, and chronic inflammation. Besides the histone modifications, sirtuins also directly modulate nonhistone substrates, including DNA repair enzymes and other repair factors.

Intriguing is the role of sirtuins in vascular homeostasis and cardiovascular disease (CVD), as they, all expressed at vascular level, take part in the normal and diseased blood vessel processes $(42,78,93,195)$. In endothelial cells (ECs), SIRT1 uniquely regulates cell physiology by controlling endothelial homeostasis and vascular functionality by modulating endothelial nitric oxide synthase (eNOS) activity, p53, angiotensin II (Ang II) type 1 receptor (AT1R), and forkhead box O (FOXO) 1. An emerging role of SIRT2 has been described in the hypertension-induced vascular remodeling (65), whereas SIRT3 controls systemic levels of oxidative stress and increases EC survival in response to hypoxia acting on FOXO3/manganese superoxide dismutase (MnSOD) signaling pathway $(96,146,195)$. SIRT4 and
SIRT7 aggravate cardiac hypertrophy and negatively affect the proliferation and migration of ECs and vascular smooth muscle cells (VSMCs) $(20,199)$. The cardioprotective role of SIRT1 and SIRT3 is common to SIRT6, a sirtuin only recently recognized to be involved in atherosclerotic plaque development $(16,110,200,218)$. However, the dual role of SIRT6 and SIRT1 as tumor promoter and tumor suppressor in cancer indicates that multiple mechanisms, to date not fully unveiled, might underlie the epigenetic activity of these sirtuins (188).

Recent developments elucidated the fine-tuned epigenetic processes mediated by SIRT1 and SIRT6 within the molecular circuitry underlying endothelial dysfunction in CVD. As for SIRT6, this sirtuin is undoubtedly an intricate lifespanregulator molecule at the crossroad in the control of cancer and CVD, as supported by recent discoveries on its roles in stem cell biology, cancer initiation and progression, heterochromatin stabilization, and metabolic homeostasis regulation $(90,99,188,172)$. Overall, both SIRT1 and SIRT6 have been recognized to play multiple functions in stress resistance, apoptosis, aging, senescence, and inflammation.

In the present review, we discuss novel insights on the cellular and molecular signalings regulated by SIRT1, the best characterized member of the sirtuin family with multiple roles in the onset and development of CVD, and SIRT6 for which novel evidence highlights the central role in the mechanisms controlling atherosclerotic plaque development.

In particular, we cover their role in the protection against oxidative stress-mediated pathological processes, including ischemia-reperfusion (I/R), cardiac damage, arterial wall remodeling, inflammation, vascular aging, and atherosclerosis.

\section{Oxidative Stress and Vascular Dysfunction}

Accumulation of reactive oxygen species (ROS), whose physiological flux regulates cellular processes essential for 
cell survival, differentiation, proliferation, and migration, is closely associated with negative outcomes in CVD by mediating cellular pathways, leading to endothelial dysfunction in diabetes, aging, inflammation, and atherosclerosis (21, 59, $127,153,161,167)$. ROS include free radical species, such as hydroxyl radical, lipid radicals, superoxide anion, nitric oxide, and other chemical species with high oxidizing potential, such as hydrogen peroxide, hypochlorous acid, and peroxynitrite $(51,52,144)$. The formation of ROS, originating from a variety of sources such as xanthine oxidases (XO), eNOS uncoupling, nicotinamide adenine dinucleotide phosphate (NADPH) oxidase isoforms, cyclooxygenases, mitochondrial respiration and metal-catalyzed reactions, along with exhaustion of antioxidant enzymes and other antioxidant defenses, results in oxidative and nitrosative stress, a key determinant of endothelial dysfunction (40, 51, 52, 60, 128, 144).

The events concurring to the development of endothelial dysfunction include oxidative stress-induced decrease in NO generation, eNOS uncoupling, elevated levels of asymmetric dimethylarginine (ADMA) because of augmented protein arginine methyl transferase-1 (PRMT1) activity, and impaired post-translational modification of eNOS, caveolin-1, and SIRT1 (7, 32). However, relationships between all events leading to oxidative stress-induced endothelial dysfunction are yet to be elucidated. In this regard, the sequestration of SIRT1 to caveolae with consequent increased acetylation of eNOS and PRMT1 leading to enhanced ADMA formation is a possible molecular mechanism (32). Multiple targets of SIRT1 and SIRT6 in cellular redox homeostasis and oxidative stress conditions are described as follows.

\section{SIRT1 and stress resistance in vascular protection}

SIRT1, highly sensitive to the cellular redox states, confers cardioprotection and maintenance of vascular function by counteracting ROS effects through the deacetylation of multiple cellular targets $(78,129,130,187)$. The redox function of the cells is directly or indirectly influenced by SIRT1, whose activity and expression, in turn, can be affected by the cellular redox state through post-translational modifications (78). Therefore, the role and action of SIRT1 in the redox-dependent cellular processes are quite complex and still under investigation.

In mammals, this sirtuin mediates the effect of calorie restriction, which delays the onset of age-associated diseases, including atherosclerosis and diabetes. The enhanced SIRT1 expression observed during the increased eNOS expression and cGMP formation in mice at 3-12 months of calorie restriction is consistent with the key regulatory role of this protein in mammal survival in response to stress (133). Through the deacetylation of eNOS at lysine (Lys)-496 and Lys-506, SIRT1 increases eNOS activity leading to enhanced production of NO, whereas SIRT1 knockdown resulted in decreased NO production and impaired endothelial-dependent vasodilatation (119).

Interestingly, a positive feedback mechanism between SIRT1 and eNOS exists, as NO is able to activate SIRT1 promoter leading to an increase of SIRT1 messenger ribonucleic acid (mRNA) and protein. In human umbilical vein ECs and in mice, cigarette smoke extract and hydrogen peroxide treatments cause a decrease in SIRT1 level and activity associated with increased acetylation eNOS and proinflammatory gene expression $(9,25,206)$.
The endothelial SIRT1 activity is promoted by apurinic/ apyrmidinic endonuclease 1/redox factor-1 (APE1/Ref-1), an important reductant in vascular homeostasis. APE1/Ref-1 protects endothelial SIRT1 from inactivation caused by hydrogen peroxide-induced oxidation of sulfhydryls and promotes SIRTcatalyzed deacetylation of eNOS, restoring NO bioavailability and endothelium-dependent vasorelaxation (82).

In human endothelium, SIRT1 antagonizes hydrogen peroxide-induced premature senescence through its negative modulation of p53 by deacetylation of Lys-373, Lys-382, and Lys-320 (84). SIRT1-dependent p53 deacetylation counteracts the effects of p300 and p300/CBP-associated factor (PCAF), which stabilizes p53 to promote cell cycle progression, senescence, and apoptosis (136). Indeed, in ECs, inhibition of SIRT1 determined an increase of p53 acetylation and caused a stress-induced premature senescence-like phenotype, in parallel with increased plasminogen activator inhibitor type 1 (PAI-1) and decreased eNOS expression. Conversely, endothelial SIRT1 overexpression reversed the stress-induced premature senescence induced by oxidative stress (136) and its overexpression attenuates hydrogen peroxide-induced cellular senescence through the eNOSdependent signaling pathway (137).

The cellular redox state is regulated by SIRT1 via deacetylation of FOXO transcription factor family, which controls the expression of several proteins responsive to oxidative stress (Fig. 2) (23, 73). SIRT1/FOXO axis mediates the contractile differentiation of VSMCs under cyclic stretch, thus contributing to maintaining vascular homeostasis (73) (Fig. 2). In response to oxidative stress, SIRT1 controls the cellular response by regulating the FOXO3 function. Deacetylation of $\mathrm{FOXO} 3$ potentiates its effect on DNA repair and cell cycle arrest, mitigating apoptotic processes (23). The stress-dependent regulation of FOXO transcription factors by SIRT1 occurs within a network involving the interaction with the tumor suppressor p53 (112).

As recently demonstrated by in vitro and in vivo models of oxidative stress, including old mice femoral arteries and murine hindlimb ischemia models, microRNA (miR)-200c decreases NO and increases acetylation of FOXO1 and p53 (29). In particular, acetylation of FOXO1 inhibits its transcriptional activity on SIRT1, catalase (CAT), and MnSOD target genes. This molecular circuitry is reinforced by the activation of mitochondrial adaptor $\mathrm{p} 66^{\mathrm{Shc}}$ and increased ROS production. Treatment with anti-miR-200c rescued SIRT1, eNOS, and FOXO1 activities and improved limb perfusion in the mouse hindlimb ischemia model, indicating that distruption of SIRT1/FOXO1/eNOS regulatory loop by miR-200c takes part in endothelial dysfunction under conditions of increased oxidative stress (29).

The known mechanisms through which $\mathrm{p} 66^{\text {Shc }}$ determines the increase of intracellular ROS levels include activation of membrane-bound NADPH oxidases and downregulation of glutathione peroxidase (GPx)-1, MnSOD, and Ref-1 (29, 33, $45,55,95,151,194)$.

SIRT1 represses the transcription of $\mathrm{p} 66^{\mathrm{Shc}}$ at the chromatin level and regulation of $\mathrm{p} 66^{\text {Shc }}$ by SIRT1 overexpression is linked to a decreased binding of the acetylated histone type 3 (H3) to the p66 $^{\text {Shc }}$ promoter region (Fig. 2) $(123,132,147$, $177,221)$. Upregulation of $\mathrm{p} 66^{\text {Shc }}$ in human ECs is linked to a significant reduction of the antioxidant enzyme SOD2, suggesting that $\mathrm{p} 66^{\mathrm{Shc}}$ mediates mitochondrial ROS production 


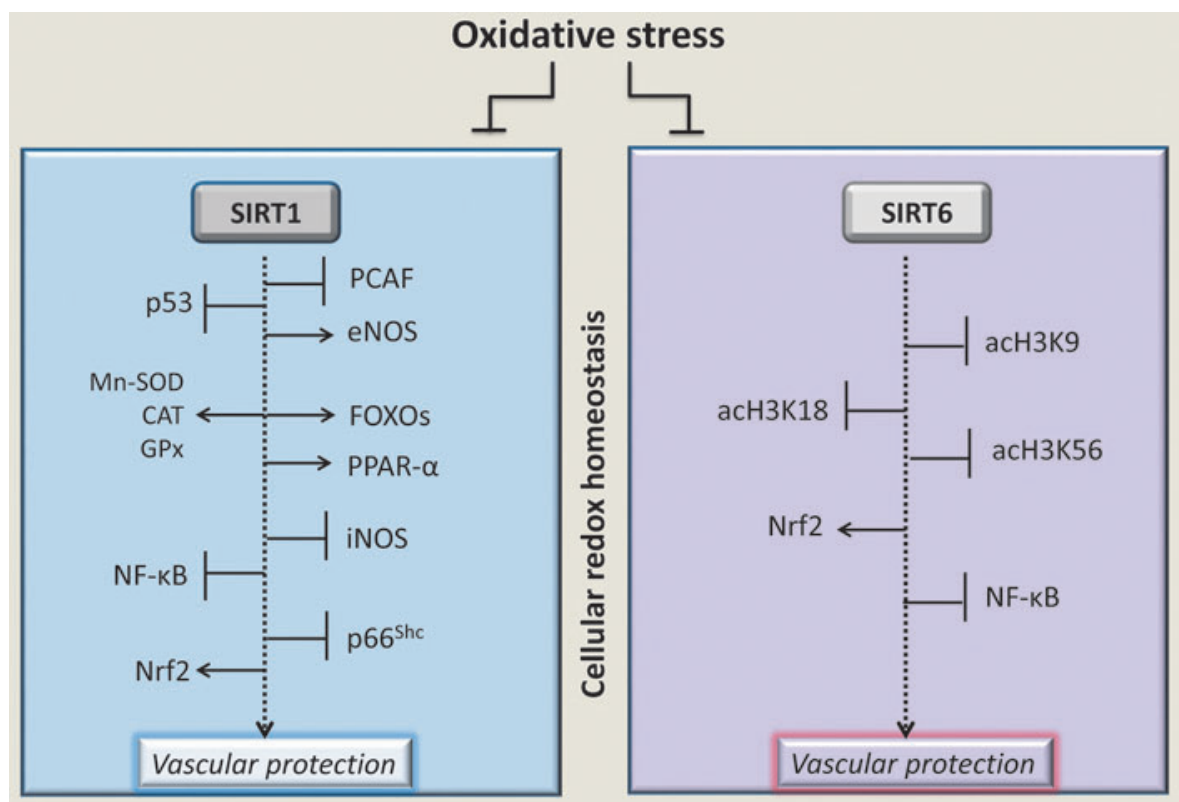

FIG. 2. SIRT1 and SIRT6 response to cellular redox status and oxidative stress. At vascular level, the physiological functions of SIRT1 and SIRT6 in the control of the cellular redox state are mediated by deacetylation of multiple targets, including histones, transcription factors (FOXO, NF- $\kappa \mathrm{B}, \mathrm{p} 53$, and Nrf2), and enzymes involved in the vascular protection. SIRT6, a highly specific histone type 3 (H3) deacetylase, targets acetylated Lys-9 (acH3K9), Lys-56 (acH3K56), and Lys18 (acH3K18). However, oxidative stress associated with various vascular pathophysiological conditions impairs SIRT1 and SIRT6 activities on their specific targets (rectangle enclosed), resulting in a decreased vascular protection against oxidative stress. $\rightarrow$, positive regulation; $\dashv$, negative regulation. CAT, catalase, eNOS, endothelial nitric oxide synthase; FOXO, forkhead box O; GPx, glutathione peroxidase; iNOS, inducible nitric oxide synthase; MnSOD, manganese superoxide dismutase; NF- $\kappa \mathrm{B}$, nuclear factor-kappa B; Nrf2, nuclear factor erythroid 2-related factor 2; PCAF, p300/CBPassociated factor; PPAR- $\alpha$, peroxisome proliferator-activated receptor coactivator 1- $\alpha$; SIRT, sirtuins.

and promotes downregulation of scavenging enzymes, leading to unopposed ROS accumulation in vascular ECs. During I/R liver injury and high-glucose-induced oxidative stress, the expression of $\mathrm{p}^{\mathrm{Shc}}$ varies inversely with that of SIRT1 (41, 203). SIRT1 overexpression increased mitochondria biogenesis and expression of CAT and GPx by peroxisome proliferator-activated receptor coactivator (PPAR) 1- $\alpha$ activation (Fig. 2) (168). SIRT1 activation also inhibited mitochondrial ROS production and reduced hydrogen peroxide levels in coronary artery ECs (179). In addition, Alcendor et al. showed that adult mice benefited from fourfold SIRT1 upregulation during moderate cardiac oxidative stress injury induced by paraquat intoxication (4).

At vascular level, a strong interaction occurs between oxidative stress and activation of redox-sensitive transcription factors, such as nuclear factor-kappa B $(\mathrm{NF}-\kappa \mathrm{B})$, leading to the characteristic proinflammatory phenotype by mediating the production of cytokines and prothrombotic markers $(11,35,141,565)$ (Fig. 2). The modulation of $\mathrm{NF}-\kappa \mathrm{B}$ signaling is affected by SIRT1-mediated deacetylation of the RelA/p65 subunit. SIRT1 interacts with RelA/ p65 protein in the NF- $\kappa \mathrm{B}$ complex and deacetylates Lys310 , an effect that correlates with a loss of NF- $\kappa \mathrm{B}$-regulated gene expression (207). Indeed, SIRT1 activators, such as resveratrol and SRT1720, ameliorate cardiac oxidative stress in diabetes, protect ECs against tumor necrosis factor$\alpha(\mathrm{TNF}-\alpha)$-induced injury, and reverse vascular endothelial dysfunction by repressing $\mathrm{NF}-\kappa \mathrm{B}$ transcriptional activity $(11,56,141)$.
Activation of endothelial nuclear factor erythroid 2-related factor 2 (Nrf2), a transcription factor that regulates key antioxidant cellular responses, is another important mechanism by which resveratrol exerts vascular protection $(180,212)$. In cultured human coronary arterial ECs, the Nrf2 transcriptional activity increased by resveratrol is associated with the upregulation of heme oxygenase-1 and NADPH-quinone oxidoreductase-1, known to protect against metabolic stress (180). Importantly, adaptive activation of the Nrf2/antioxidant responsive element pathway confers endothelial protection under hyperglycemia-induced oxidative stress, as Nrf2 knockdown abrogates resveratrol-mediated reduction of mitochondrial and cellular oxidative stress (178).

Similarly, the long-lasting antioxidant and antiaging effects of molecular hydrogen on ECs treated with 2,3,7,8tetrachlorodibenzo-p-dioxin, a family of dioxins mediating blood vessel inflammation and premature senescence, occur through the activation of Nrf2 and are paralleled by a positive modulation of SIRT1 activity until $24 \mathrm{~h}$ of exposure (64). Although a direct interaction between Nrf2 and SIRT1 has been described in other cell models (87), it has yet to be proven in ECs. However, it cannot be ruled out that, beside possible indirect mechanisms, SIRT1 might act as a direct modulator of Nrf2-driven responses in the vasculature (66).

\section{Redox regulation of SIRT6 in vascular protection}

The relationship between SIRT6 and redox resistance is intriguing and not yet fully clarified. SIRT6 has been well 
characterized as a highly specific $\mathrm{H} 3$ deacetylase that targets Lys-9 (H3K9), Lys-56 (H3K56), and Lys-18 (H3K18) (Fig. 2) $(86,121,122,140,171)$, as confirmed by Wang et al. through a novel approach to generate nucleosomes specifically acetylated on a single specific site (191). It has been hypothesized that, under oxidative and nitrosative stress, SIRT6 activity can be regulated via reactive nitrogen species-mediated posttranslational modifications (71). Indeed, incubation of purified recombinant SIRT6 protein with 3-morpholinosydnonimine, a donor of peroxynitrite, increased nitration at tyrosine 257 and decreased the catalytic activity (71).

As recently revealed, in response to oxidative stress, SIRT6 is phosphorylated on serine (Ser)-10 by the stressactivated c-Jun N-terminal kinase ( JNK), followed by a rapid recruitment of SIRT6 to the double-strand break site and the simultaneous activation of the SIRT6-mediated mono-ADP ribosylation of poly-(ADP-ribose) polymerase 1 (PARP1) (182). SIRT6-deficient $\left(\mathrm{SIRT6}^{--}\right.$) human mesenchymal stem cells showed increased ROS levels, dysregulated redox metabolism, and increased sensitivity to oxidative stress (139). However, transcriptional changes in human vascular ECs were not affected by SIRT6 depletion, suggesting that cell type differences may underlie the divergent phenotypes. Indeed, the coordinated downregulation of Nrf2 target genes in SIRT6 ${ }^{-1-}$ human mesenchymal stem cells was not observed in SIRT6 ${ }^{-1-}$ human vascular ECs $(103,139)$ (Fig. 2).

Evidence of SIRT6 involvement in vascular protection comes from several studies showing that SIRT6 deficiency raises the expression of endothelial proinflammatory cytokines and increases $\mathrm{NF}-\kappa \mathrm{B}$ transcriptional activity $(16,41$, 97, 109). The protective effect of SIRT6 against premature endothelial senescence is exerted through a fine control of the expression of intercellular adhesion molecule-1 (ICAM-1), PAI-1, p21 Cip1/Waf1, and eNOS (28) (Fig. 2).

\section{Inflammation and Vascular Aging}

Oxidative stress and inflammation are main interplaying events in the development of vascular aging, a multifactorial process modulated by multiple cellular events $(51,196)$. This process relates to structural and functional changes in the vasculature, including dilated lumen, altered intimal-medial thickness, endothelial dysfunction, increased endothelial apoptosis, dysregulation of matrix metalloproteinase (MMP), production of inflammatory cytokines, and increased ROS production. In particular, oxidative stress and low-grade inflammation are key changes occurring in the artery with age (51). Main mechanisms involved in the vascular "inflammaging" process include NF- $\kappa \mathrm{B}$, activator protein-1 (AP-1), p53, p27, p66 ${ }^{\text {Shc }}$, AMP-activated protein kinase (AMPK), and Nrf2 signalings $(4,40,51,92,196)$, some of which are part of SIRT1 and SIRT6 networks, as discussed in the ensuing sections.

\section{SIRT1 in cell senescence and aging processes}

Multiple in vitro and in vivo evidence highlights the protective role of SIRT1 against vascular aging. SIRT1 expression markedly decreases in vascular tissues undergoing senescence and its deficiency in ECs, VSMCs, and monocytes/macrophages accelerates vascular aging, contributing to increased inflammation, oxidative stress, endothelial dysfunction, foam cells formation, and autophagy $(41,48,78,93)$.
During the aging-related downregulation of SIRT1, a malfunction of SIRT1-eNOS axis can explain the impaired NO production $(29,120,136,137)$. Indeed, SIRT1 protection against ROS-induced premature senescence is accompanied by increased eNOS activity, as supported by observations that the endogenous inhibitor of SIRT1, miR-217, suppresses eNOS activity with a concomitant progression of endothelial senescence (Fig. 3) $(120,136,137)$. Similar to ECs, the senescence of endothelial progenitor cells (EPCs) also negatively correlates with the expression and activity of SIRT1 $(98,145)$. Indeed, in heterozygous methylene tetrahydrofolate reductase-deficient mice, the generation of ROS via eNOS uncoupling leads to SIRT1 downregulation and increases EPC senescence (98).

In the course of inflammatory processes underlying the initiation and progression of vascular aging, ECs and activated immune cells undergo a chronic activation of NF- $\kappa \mathrm{B}$ signaling. In this regard, reduced levels of SIRT1 lead to an increased acetylation of Lys-310 on the p65 subunit of NF- $\kappa \mathrm{B}$, resulting in an increased inflammatory response in ECs and monocytes/macrophages $(11,35,56,141,150,163,207,208)$.

SIRT1 activation with SRT1720 normalized SIRT1 expression/activity in old mice and improved the endothelial function by reducing oxidative stress, NF- $\kappa \mathrm{B}$ activation, and TNF- $\alpha$ levels and by enhancing cyclooxygenase-2-mediated dilation and protein expression in the absence of changes in nitric oxide bioavailability (56). In contrast, decreased levels of inflammatory markers and activation of SIRT1 have been observed in obese male patients after 7 weeks of calorie restriction (92).

In ECs, increased cyclin-dependent kinase 5-mediated hyperphosphorylation of SIRT1 at Ser-47 prevents its nuclear exportation and the interaction with telomeric repeat-binding factor 2-interacting protein 1 (TERF2IP), a regulator of telomere function and NF- $\kappa \mathrm{B}$ signaling (12).

Other factors blocked by SIRT1, including p53, PAI-1, and p66 ${ }^{\text {Shc }}$, take part in the protection against endothelial senescence (Fig. 3) (85, 106, 145, 189, 221).

A reduced SIRT1 expression and an increased acetylation of p53 at Lys-382 have been reported in patients with chronic obstructive pulmonary disease, showing an increased EPC senescence (145). A recent study including 358 patients with a smoking history of $>10$ pack-years showed decreased SIRT1 mRNA levels and number of EPCs (85).

Another marker of endothelial senescence, PAI-1, is also inhibited by SIRT1 through an epigenetic regulatory mechanism involving the reduction of acetylated histone 4 Lys-16 (H4K16) on the PAI-1 promoter $(106,189)$. Indeed, in senescent ECs and aortas of old mice, improved endothelial function and reduced arterial stiffness have been observed during SIRT1 overexpression that reverses the increased PAI-1 levels (189).

Moreover, in aging mice, a decline of SIRT1 activity because of a compromised phosphorylation at Ser-154 accounts for the reduced expression of endothelium estrogen receptor $\beta(\mathrm{ER} \beta)$ via binding of SIRT1-PPAR- $\gamma / \mathrm{RXR}-\mathrm{p} 300$ to a PPAR response element site on the $\operatorname{ER} \beta$ promoter (94). Consistent with the role of SIRT1 against endothelial senescence, a mouse model of vascular senescence created by genetically ablating exon 4 of SIRT1 in ECs (SIRT1 ${ }^{\text {endo- }{ }^{-}}$) showed impaired endothelium-dependent vasorelaxation and angiogenesis (183). More recently, another molecular mechanism 


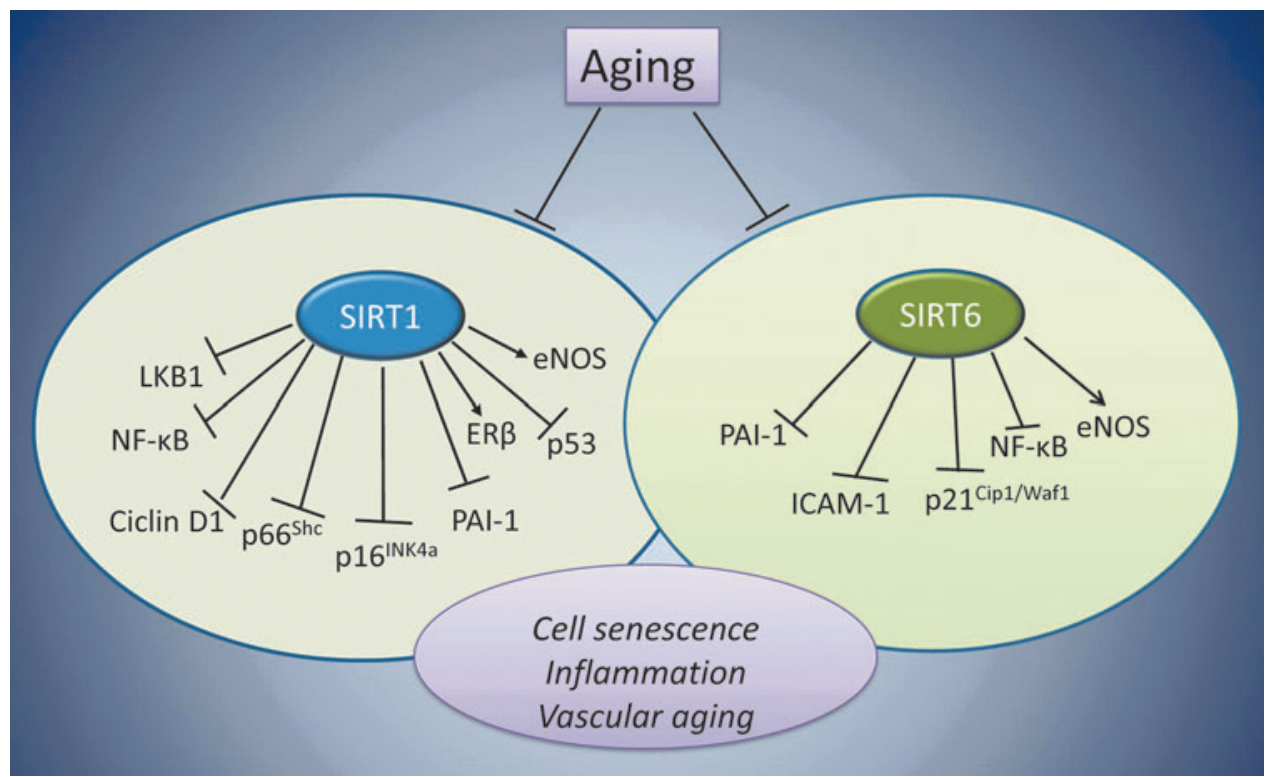

FIG. 3. SIRT1 and SIRT6 in vascular aging. Aging processes, by blocking all cellular signals controlled by SIRT1 and SIRT6 (circle enclosed), lead to vascular aging. SIRT1 and SIRT6 deacetylate their specific and common substrates, including histone and nonhistone molecules, thus improving genome stability and preventing cell senescence. SIRT1 regulates eNOS via transcriptional and post-transcriptional deacetylation, resulting in the NO-mediated vascular protection. SIRT1 and SIRT6 control inflammation by deacetylating the p65 subunit of NF- $\kappa$ B, thus inhibiting the expression of inflammation-related genes, including ICAM-1, as well as proinflammatory cytokines. In ECs, SIRT6 protects from senescence and oxidative stress by blocking p $21^{\text {Cip } 1 / \text { Waf } 1}$ signaling and sustaining high eNOS levels. The crosstalk between sirtuins and senescence-related proteins, such as $\mathrm{p} 66^{\mathrm{Shc}}$, prevents vascular diseases based on antioxidative stress responses. $\rightarrow$, positive regulation; $\dashv$, negative regulation. ECs, endothelial cells; ICAM-1, intercellular adhesion molecule-1.

underlying the preventive effect of SIRT1 against endothelial senescence and vascular aging has been demonstrated, showing that SIRT1 prevents endothelial senescence by downregulating acetylation of stress-responsive serine/threonine liver kinase B1 (LKB1) via HERC2, a giant scaffold protein, and E3 ubiquitin ligase (Fig. 3) (13). In aged arteries or senescent ECs, an increased nuclear accumulation of acetylated LKB1 is observed when SIRT1 expression and function are lost with concomitant irreversible alterations of vascular stiffness, blood vessel wall, and adverse arterial remodeling, suggesting that the SIRT1/HERC2/LKB1 complex fine tunes the crosstalk between endothelial and VSMCs to maintain vascular homeostasis (13). Conversely, SIRT1 overexpression and increased LKB1deacetylation prevented the EC senescence in vitro, as well as the stress-induced senescence in mice (221).

In the intima of injured carotid arteries, SIRT1 overexpression markedly inhibits VSMC proliferation and migration, and decreases cyclin D1 induction and MMP-9 expression (Fig. 3) (100). Moreover, downregulation of SIRT1 by miR-34a promotes senescence and inflammation in VSMCs isolated from old mice aortas (10). Similar evidence comes from rat superior mesenteric artery model, in which homocysteine-induced upregulation of type B endothelin is linked to SIRT1 downregulation and activation of $\mathrm{NF}-\kappa \mathrm{B}$ signaling in VSMCs (36). An inverse correlation between SIRT1 expression in VSMCs isolated from human arteries and the age of donors, ranging from 12 to 82 years, has been reported (175). This difference is even more marked in human VSMCs isolated from aged and occluded arteries with atherosclerotic lesions compared with nonoccluded sections of the same artery, suggesting that the reduced SIRT1 expression may be determinant in the development and progression of vascular aging and atherosclerosis.

\section{SIRT6 in aging-related endothelial dysfunction}

The role of SIRT6 in DNA repair, chromatin compaction, telomerase function, and genomic stability places this protein at the forefront against cellular senescence (172). SIRT6, by acting as a corepressor of several transcription factors implicated in aging, promotes chromatin changes essential for DNA repair during DNA damage and maintains telomeric chromatin structure to prevent genomic instability and cellular senescence. Indeed, the stably knocked-down SIRT6 expression in human fibroblasts leads to genomic instability and premature cellular senescence in response to telomere sequence loss (121).

The stabilization of repressive heterochromatin carried out by SIRT6 at subtelomeric regions determines the silencing of telomere-proximal genes, and deregulation of such genes contributes to cellular changes in aging (173). In male mice, the extended lifespan linked to SIRT6 overexpression relates to a decrease in serum insulin-like growth factor (IGF-1) and increase in IGF-binding protein 1 (83). SIRT6 prevents genomic instability and aging-related cellular dysfunction by maintaining heterochromatin at long interspersed element-1 (LINE-1) retroelements, suppressing their transcription, and preventing retrotransposition events destabilizing the genome (89). Indeed, the SIRT6-dependent heterochromatin packaging of heterochromatin at LINE-1 retroelements suppresses the transposition, a function that can be compromised 
during aging (181). Furthermore, SIRT6-dependent H3 Lys18 deacetylation maintains pericentric heterochromatin silencing $(171,172)$. Moreover, accumulation of pathological pericentric transcripts in SIRT6-deficient cells is involved in aging, genomic instability, and cellular senescence (171, 172). In human fibroblast, deacetylation of $\mathrm{p} 27^{\mathrm{Kip} 1}$ by SIRT6 results in delayed cellular senescence (219).

At vascular level, SIRT6 protects ECs against premature senescence by preserving their replicative capacity and ability to form in vitro vessels. In ECs, downregulation of SIRT6 occurs during hydrogen peroxide-induced cell senescence, whereas SIRT6 overexpression partially reverses this process (109). SIRT6 knockdown determines an accelerated cell senescence and overactive NF- $\kappa \mathrm{B}$ signaling, thus disclosing the critical role of SIRT6 on aging and inflammation (211). SIRT6 protein silencing by siRNA causes the inhibition of EC replication and increases EC senescence (28). Upregulation of PAI-1, p21 Cip1/Waf1, and ICAM-1 mRNA levels has been observed after SIRT6 depletion, which also causes a decreased eNOS expression and ability of ECs to form in vitro vessels (Fig. 3) (28).

\section{Sirtuins and Altered Glucose Homeostasis}

Increased ROS levels and reduced NO bioavailability play a key role in the induction and progression of microvascular and cardiovascular complications during diabetes $(143,155)$. The metabolic milieu in diabetes, including hyperglycemia, dyslipidemia, insulin resistance, and hyperinsulinemia, induces a vicious circle of events in the vascular wall and causes overactivation of several biochemical pathways, contributing to increased oxidative stress, apoptosis and vascular permeability, and a low-grade proinflammatory condition via activation of the NF- $\kappa \mathrm{B}$ signaling $(143,155)$. Hyperglycemia negatively affects levels and activities of SIRT1 and SIRT6 and their respective molecular targets, thus reducing their vascular protective effects $(1,42,195)$.

\section{SIRT1, glucose homeostasis, and hyperglycemia}

SIRT1, a positive regulator of insulin secretion, triggers glucose uptake and utilization, thus representing a target of choice for therapeutics in diabetes $(1,77)$. In the current proposed mechanisms controlling diabetic complications within the context of aging, FOXO3 and the SIRT1-LKB1AMPK cascade create a positive feedback through $\mathrm{NAD}^{+}$ synthesis to help residential adult stem cells to cope with metabolic stress (79).

Hyperglycemia causes a p66 ${ }^{\text {Shc }}$-mediated endothelial dysfunction. Mice lacking p66 $6^{\text {Shc-l- }}$ gene display reduced production of intracellular oxidants and are protected from age-dependent endothelial dysfunction and age-related risk factors, such as diabetes and hypercholesterolemia (26). In particular, high-glucose induces a significant hypomethylation of $\mathrm{CpG}$ dinucleotides, leading to an upregulated $\mathrm{p} 66^{\mathrm{Shc}}$ transcription. Hyperglycemia, along with dyslipidemia and insulin resistance, also affects $\mathrm{NO}$ and stromal cell-derived factor-1/C-X-C chemokine receptor type 4 pathways and SIRT1/p53/p66 ${ }^{\text {Shc }}$ axis, contributing to dysregulation of EPCs in terms of number, mobilization, migration, and homing capacities (194). Delivery of adenoviral vectors encoding SIRT1 into the hearts of diabetic rats markedly increased SIRT1 expression and was accompanied by a reduced cardiomyocyte apoptosis, superoxide generation, and by a simultaneous eNOS activation (46).

SIRT1 protects blood vessels from hyperglycemiainduced endothelial dysfunction through a mechanism involving the downregulation of $\mathrm{p} 66^{\text {Shc }}$ and PAI- 1 expression $(142,221)$. In vitro and in vivo models demonstrated that SIRT1 inhibits the high-glucose-induced $\mathrm{p} 66^{\text {Shc }}$ expression, at both mRNA and protein levels, via a specific binding to the p66 ${ }^{\text {Shc }}$ promoter, resulting in a decreased acetylation of $\mathrm{H} 3$ at the promoter region (221). Indeed, endothelium-specific SIRT1 transgenic diabetic mice showed a decreased p66 ${ }^{\text {Shc }}$ expression accompanied by reduced oxidative stress and improved endothelial function (Fig. 4).

Hyperglycemia and free fatty acid increase upregulate endothelial miR-34a via a p66 ${ }^{\text {Shc }}$-dependent mechanism, leading to endothelial dysfunction by targeting SIRT1. In particular, aortic endothelium of $\mathrm{db} / \mathrm{db}$ and streptozotocininduced diabetic mice show miR-34a upregulation along with SIRT1 downregulation via $\mathrm{p}^{\text {Shc }}$ signaling. Interestingly, impaired endothelium-dependent vasorelaxation caused by miR-34a is ameliorated by SIRT1 overexpression, and blocking endothelial miR-34a by genetic ablation or systemic infusion of specific inhibitor prevents the high-glucoseinduced SIRT1 downregulation (101).

In ECs, the inhibition of high-glucose-induced SIRT1 downregulation by the dietary antioxidant ergothioneine, the betaine of 2-mercapto-L-histidine, resulted in the downregulation

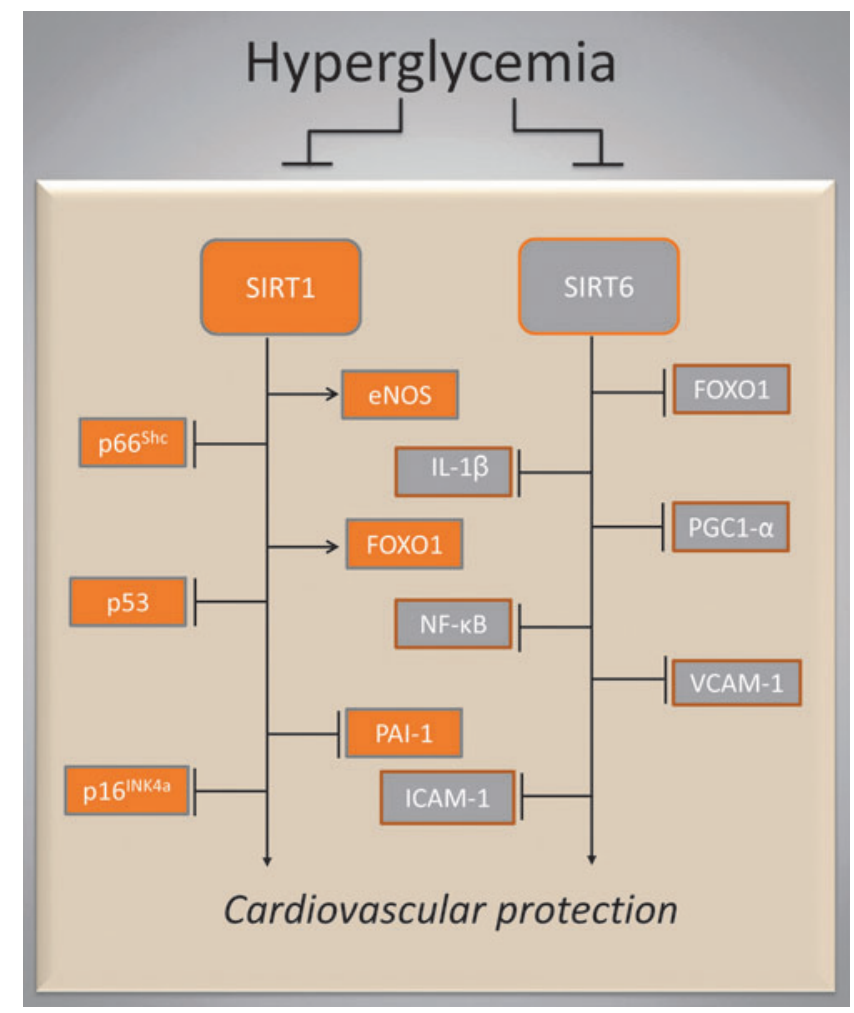

FIG. 4. SIRT1 and SIRT6 during altered glucose homeostasis. Hyperglycemia downregulates SIRT1- and SIRT6-controlled signaling pathways (rectangle enclosed). The diverse functions of SIRT1 and SIRT6 in nutrient sensing determine a fine adjustment of glucose homeostasis. $\rightarrow$, positive regulation; $\dashv$, negative regulation. 
of $\mathrm{p} 66^{\text {Shc }}$, the reduction of the intracellular ROS production, and in the protection against cell senescence (41). The decreased expression of SIRT1 in ECs exposed to high-glucose conditions is also paralleled by an increased expression of $\mathrm{p} 16^{\mathrm{INK} 4 \mathrm{a}}$ and $\mathrm{p} 53$ activation (Fig. 4) (135, 158). In cultured human umbilical vein ECs, post-transcriptional stabilization of SIRT1 by HuR, an embryonic lethal, abnormal vision, Drosophila family RNAbinding protein, represses inflammation- and hyperglycemiainduced E-selectin release (31).

Diabetic conditions relate to $\mathrm{p} 16^{\text {INK4a }}$ and p53 activation also in EPCs (221), whose number and function are severely impaired by hyperglycemia. In vitro short-term exposure of EPCs to high-glucose, which impairs their number and functionality, determines SIRT1 downregulation, reduces FOXO1 deacetylation, and reduces eNOS phosphorylation (Fig. 4) (15, 220). Consistent with these findings, in vitro and ex vivo studies demonstrate that poor glycemic control in type 2 diabetes patients reduces number of EPCs and differentiation capability by blocking SIRT1 signaling $(3,17,116)$. Interestingly, SIRT1 downregulation and number of EPCs were improved in hyperglycemic patients after a tight periprocedural glycemic control during early percutaneous coronary intervention (116). Altered EPC mobilization via dysregulated $\mathrm{p}^{66 \mathrm{Shc}} / \mathrm{SIRT} 1$ axis has also been demonstrated in diabetic patients with bone marrow autonomic neuropathy (3) (Fig. 4).

\section{SIRT6 and glucose metabolism control}

The essential role of SIRT6 in maintaining glucose homeostasis was first revealed by evidence showing that severe hypoglycemia of SIRT6-deficient mice was associated with increased glucose uptake and insulin signaling (83). SIRT6 modulates glucose metabolism by $\mathrm{H} 3$ Lys-9 deacetylation in promoters of glycolytic genes and functioning as a corepressor of hypoxia-inducible factor $1-\alpha$.

Interestingly, Anderson et al. showed that, in mice fed highfat or high-calorie diets, overexpression of SIRT6 protects against defects in glucose tolerance, glucose-stimulated insulin secretion, and insulin sensitivity (6). Notably, SIRT6 inactivation in mice liver leads to fatty liver formation because of increased synthesis of triglycerides (TG) and glycolysis.

Inactivation of SIRT6 in mouse pancreatic beta cell line leads to impaired glucose-stimulated insulin secretion and insulin sensitivity, supporting an SIRT6 role in promoting beta cell insulin secretion (198). In addition, mice with brainspecific ablation of SIRT6 had low-growth hormone $(\mathrm{GH})$ and IGF-1 levels, suggesting that, in some physiological contexts, SIRT6 may also impact glucose metabolism and insulin sensitivity through $\mathrm{GH} / \mathrm{IGF}-1$ signaling (154).

SIRT6 controls gluconeogenesis through proliferatoractivated receptor $\gamma$ coactivator- $1 \alpha$ (PGC- $1 \alpha)$ and p53/ FOXO1 signaling $(47,213)$. In diabetic $\mathrm{db} / \mathrm{db}$ mice, SIRT6 suppresses hepatic gluconeogenesis and prevents hyperglycemia by repressing PGC- $1 \alpha$ activity via acetyltransferase GCN5. In particular, SIRT6 deacetylates GCN5, and this deacetylation, accompanied by changes in phosphorylation state of GCN5, enhances its acetyltransferase activity causing an increase in the acetylation of PGC- $1 \alpha$ (47).

Endothelial SIRT6 deficiency and SIRT6 gene silencing by small interfering RNA determine the increased expression of proinflammatory cytokines, such as interleukin (IL)-1 $\beta$, and an increased transcriptional activity of NF- $\kappa \mathrm{B}$ (Fig. 4)
(97, 151). In line with this evidence, fibroblast cultured in low-glucose conditions shows resistance to cell senescence and enhanced SIRT6 expression by attenuating NF- $\kappa \mathrm{B}$ signaling (211). Moreover, SIRT6-siRNA treateatment of cutaneous wound in diabetic mice promotes NF- $\kappa \mathrm{B}$ activation and results in increased oxidative stress and proinflammatory marker expression, including ICAM-1, vascular cell adhesion molecule-1 (VCAM-1), TNF- $\alpha$, and IL-1 $\beta$ (174).

\section{Protective Role of SIRT1 and SIRT6 in Atherosclerosis}

Aging processes contribute to the pathogenesis of atherosclerosis, the most frequent cause of CVD deaths in the elderly and in patients with diabetes mellitus, dyslipidemia, metabolic syndrome, and hypertension (57, 104). Atheroclerosis is promoted by SIRT1 deficiency in ECs, VSMCs, and monocyte/macrophages, which actively mediates oxidative stress, inflammation, foam cell formation, and impaired autophagy in vascular wall (93). In this regard, severe autophagy stimulated by high inflammation or oxidative stress leads to reduced collagen synthesis, fibrous cap thinning, plaque destabilization, restenosis, and acute coronary syndrome. Intriguingly, beside SIRT1, the link between SIRT6 and atherosclerotic plaque vulnerability has been unveiled only recently $(16,44,110,200,218)$.

\section{SIRT1 and atherosclerosis}

SIRT1 exerts an atheroprotective effect by increasing NO production, HERC2-mediated degradation of LKB1, blocking the NF- $\kappa \mathrm{B}$-mediated inflammatory process, reducing oxidative stress, and controlling autophagy $(93,204)$. In apolipoprotein $\mathrm{E}$ knock-out $\left(\mathrm{ApoE}^{-/-}\right)$mice, the impaired endothelium-dependent vasorelaxation was improved in SIRT1-transgenic mice and accompanied by aortic eNOS upregulation $(8,214)$ (Fig. 5). Specifically, endothelialspecific overexpression of SIRT1 in $\mathrm{ApoE}^{-/-}$mice activates eNOS expression, prevents expression of endothelial adhesion molecules, and attenuates aortic plaque development in response to high-fat diet (214).

In line with this evidence, upregulation of aortic eNOS and SIRT1 expression in hypercholesterolemic mice after oral administration of low doses of red wine, as a source of resveratrol, supports the implications of SIRT1 in the prevention of atherosclerotic lesion progression (131). Levels and activity of SIRT1 have also been found to be significantly decreased in lungs of atherosclerosis-prone $\mathrm{ApoE}^{-/}$mice with further reduction in response to cigarette smoke, causing lung endothelial dysfunction caused by increased acetylation and inactivation of eNOS (9). Moreover, SIRT1 counteracts the neointima formation through the repression of AP-1 activity and the decreased expression of cyclin D1 and MMP-9 (Fig. 5) (100).

At the VSMC level, SIRT1 protects against DNA damage and inhibits atherosclerosis, in part, through activation of the repair protein Nijmegen breakage syndrome-1 (NBS-1) (58). Interestingly, ApoE ${ }^{-/-}$mice expressing inactive truncated SIRT1 $(\Delta$ ex 4$)$ in smooth muscle cells showed increased atherosclerosis and reduced relative fibrous cap thickness and medial degeneration (Fig. 5). In subjects with type 2 diabetes, atherosclerotic plaques are characterized by increased MMP9 activity and decreased tissue inhibitor of metalloproteinase 3 (TIMP3) expression, with the reduced expression of TIMP3 


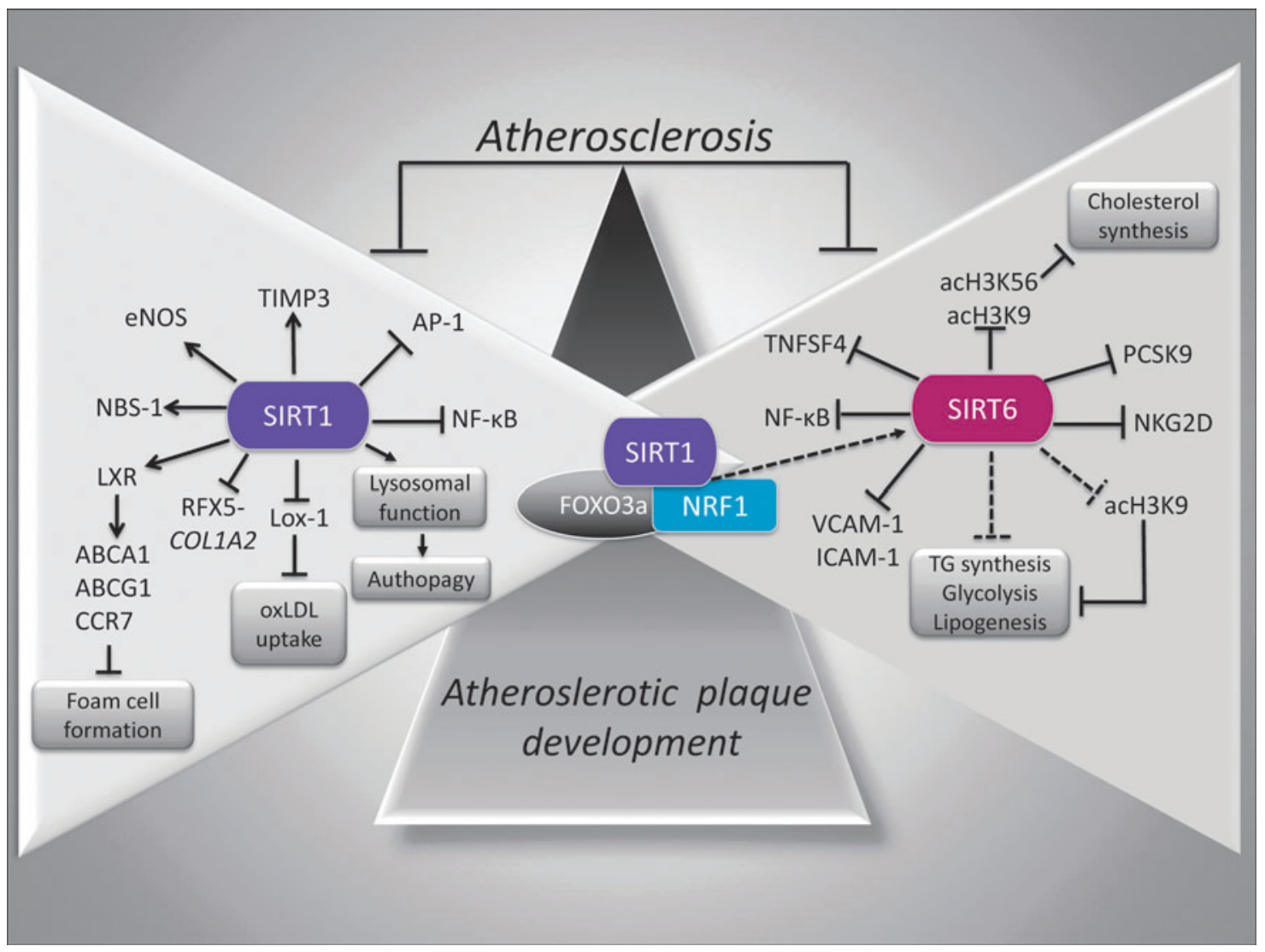

FIG. 5. SIRT1 and SIRT6 protection in atherosclerosis. Molecular pathways controlled by SIRT1 and SIRT6 (triangle enclosed) allow the reduction of NF- $\kappa \mathrm{B}$ activation, the oxLDL uptake by downregulation of Lox-1 expression, TG and hepatic cholesterol synthesis, and suppression of foam cell formation via deacetylation and subsequent activation of LXR. SIRT6 targets histone type 3 (H3) acetylated Lys-9 (acH3K9) and Lys-56 (acH3K56). $\rightarrow$, positive regulation; -1 , negative regulation. Lox-1, lectin-like oxLDL receptor 1; LXR, liver X-receptor; oxLDL, oxidized low-density lipoproteins; TG, triglycerides.

associated with reduced SIRT1 levels (27). In particular, in smooth muscle cells, SIRT1 overexpression increased TIMP3 promoter activity, whereas inhibition of SIRT1 activity reduced TIMP3 expression (Fig. 5). Importantly, in smooth muscle cells, SIRT1 maintains collagen synthesis and prevents plaque to become unstable and more prone to rupture by promoting nuclear expulsion and proteasomal degradation of the regulatory factor for X-box (RFX5) activity, hence dampening its binding to the collagen type I (COL1A2) gene promoter (197).

In response to atheroprotective pulsatile shear stress, the coregulation of AMPK and SIRT1 by $\mathrm{Ca}^{2+} /$ calmodulindependent protein kinase kinase $\beta(\mathrm{CaMKK} \beta)$ contributes to an atheroprotective phenotype. In the proposed cellular mechanism, AMPK and SIRT1 act in concert in the cytoplasm to activate eNOS, thereby activating NO-mediated anti-inflammatory effects by repressing monocyte chemotactic protein-1 (MCP-1), VCAM-1, ICAM-1, and E-selectin. Moreover, in the nucleus, AMPK and SIRT1 activate PGC$1 \alpha$, leading to upregulation of the antioxidant enzymes, SOD, and CAT (193). The AMPK/NADPH-oxidase/Akt/eNOS signaling pathway is also modulated by quercetin, an antioxidant that activates SIRT1 and suppresses the endothelial oxidative injuries induced by oxidized-low density lipoproteins (oxLDL) (76). Similar to quercetin, resveratrol attenu- ates vascular endothelial inflammation and oxLDL-induced injury by upregulating the AMPK/SIRT1 or CAMP-PRKAAMPK-SIRT1 signaling pathways $(34,61,81,138)$. In particular, oxLDL inhibits the autophagic flux through a mechanism involving the oxLDL-induced SIRT1-dependent lysosomal dysfunction $(216,217)$.

The atheroprotective effect of SIRT1 is also exerted through the fine modulation of EPC senescence and adventitial fibroblast migration $(107,124)$. In particular, in EPCs, the nicotinamide phosphoribosyltransferase (NAMPT), the rate-limiting enzyme in the $\mathrm{NAD}^{+}$biosynthetic pathway, attenuates oxLDL-induced senescence by upregulating SIRT1 expression through the PI3K/Akt/ERK pathway (124). In peripheral blood mononuclear cells from subjects with metabolic syndrome, the high-glucose- and palmitate-dependent impairment of SIRT1 are linked to reduction of NAMPT expression, consequent depletion of cellular NAD ${ }^{+}$, and increased ROS generation (43).

A key event in atherogenesis is represented by the infiltration of monocyte-derived macrophages into the subendothelial space. The uptake of oxLDL through the scavenger receptor lectin-like oxLDL receptor 1 (Lox-1) determines the accumulation of cholesterol in macrophages and consequent formation of foam cells. SIRT $1^{+/+} \mathrm{ApoE}^{-/-}$mice showed reduced macrophage foam cell formation and oxLDL uptake 
accompanied by diminished Lox-1 expression via NF- $\kappa \mathrm{B}$ signaling pathway (162) (Fig. 5). Consistently, increased SIRT1 and decreased Lox-1 expression levels have also been observed in oxLDL-stimulated human umbilical vein ECs exposed to ginkgolide $\mathrm{B}$, an inhibitor of the platelet-activating factor with anti-inflammatory properties elicited via NF- $\kappa \mathrm{B}$ inhibition and reduced ICAM-1 and MCP-1 expression (113). Interestingly, Lox-1 regulation of in vivo thrombus formation depends on the degree of activation by oxLDL. Specifically, Lox-1 activates the protective SIRT1 pathway at low levels of oxLDL, whereas it switches to the thrombogenic ERK1/2-dependent pathway at higher levels of oxLDL (2).

SIRT1 controls foam cell formation by deacetylating and activating liver X-receptor (LXR), which, in turn, upregulates the ATP-binding cassette subfamily A member (ABCA) 1 and ATP-binding cassette subfamily G member (ABCG) 1, as well as $\mathrm{C}-\mathrm{C}$ chemokine receptor 7 (CCR7), thereby promoting the reverse cholesterol transport and slowing foam cell formation (102) (Fig. 5).

\section{SIRT6 and atherosclerotic plaque formation}

SIRT6 represses TG synthesis and fat metabolism, promotes fatty acid $\beta$-oxidation, and maintains low levels of LDL cholesterol by deacetylating $\mathrm{H} 3$ at Lys-9 (H3K9) in the promoter of several genes involved in these metabolic processes (91).

Upon nutritional stress, SIRT6 is positively modulated by SIRT1 through the formation of the SIRT1/FOXO3a/nuclear respiratory factor 1 (NRF1) complex on the promoter of SIRT6, which, in turn, negatively regulates TG synthesis, lipogenesis, and glycolysis (Fig. 5) (91).

Accordingly, SIRT6-mediated histone deacetylation represses the transcription of proprotein convertase subtilisin/ kexin type 9 (PCSK9) and sterol regulatory element-binding proteins (SREBPs) 1 and 2 transcriptional regulators (Fig. 5). Specifically, SIRT6 and FOXO3 can coordinate to regulate cholesterol homeostasis via FOXO3-mediated recruitment of SIRT6 by the $S R E B P 1 / 2$ gene promoter, wherein it deacetylates H3 at Lys-9 (H3K9) and Lys-56 (H3K56) and promotes a repressive chromatin state (170). Moreover, cholesterol metabolism is regulated by SIRT6 via repression of lipogenic transcription factors SREBP1 and SREBP2 and their target genes, the inhibition of SREBP1/SREBP2 cleavage into their active forms, and the activation of AMPK that phosphorylates and inhibits SREBP1 (53).

The direct involvement of SIRT6 in atherosclerotic plaque development emerged recently from ex vivo and in vivo evidence in diabetic patients and in animal models of atherosclerosis (16, $110,200,218)$. Indeed, carotid atherosclerotic plaques from type 2 diabetic patients displayed reduced SIRT6 expression compared with plaques from nondiabetic patients (16). In particular, in diabetic atherosclerotic lesions, the downregulated SIRT6 protein expression was associated with decreased interstitial collagen content and increased levels of oxidative stress, NF- $\kappa \mathrm{B}$, proinflammatory cytokine, and MMP-9 (Fig. 5) (16). All these molecular events characterizing the phenotype of atherosclerotic carotid plaque from asymptomatic type 2 diabetic patients are positively modulated by therapy with glucagon-like peptide-1 receptor agonists, a novel class of antihyperglycemic agents showing pleiotropic effects on the artery wall function.

Accordingly, in vitro short-term exposure of EPCs and ECs to high-glucose induced a downregulation of SIRT6 and upregulation of NF- $\kappa \mathrm{B}$ (16). In vivo studies in animal models of atherosclerosis supported the role of SIRT6 as a negative regulator factor in endothelial dysfunction and atherosclerosis development. Indeed, SIRT6 gene and protein expression have been shown to be downregulated in atherosclerotic plaques of $\mathrm{ApoE}^{-/-}$mice fed high-cholesterol diet (110). In particular, SIRT6 knocked down $\mathrm{ApoE}^{-/-}$mice showed impaired endothelium-dependent vasodilation, increased plaque size, and augmented plaque vulnerability, evidenced by increased necrotic core areas, macrophage accumulation, and reduced collagen content.

Accordingly, SIRT6 heterozygous $\left(\right.$ SIRT6 $^{+/-}$) mice showed an increased expression of natural-killer group 2 member D (NKG2D) ligand on macrophages and ECs leading to natural killer cell activation and increased levels of inflammatory cytokines (Fig. 5) (218). Finally, another key evidence of the atheroprotective role of SIRT6 derives from the observation that SIRT6 ${ }^{+/} / \mathrm{ApoE}^{-/-}$mice fed a high-fat diet show impressive atherosclerotic lesion development, together with increased expression of the proinflammatory cytokine VCAM-1 (200).

Analysis of potential SIRT6 target genes indicated that SIRT6 binds to proatherogenic tumor necrosis factor superfamily member 4 (TNFSF4) gene promoter wherein it deacetylates $\mathrm{H} 3 \mathrm{~K} 9$, resulting in SIRT6-dependent repression of TNFSF4 transcription in ECs (Fig. 5) (200). However, it still remains to be seen whether SIRT6 overexpression and/or modulation by specific activators are able to rescue vascular inflammation and retard atherosclerotic plaque development.

More recently, SIRT6 has been shown to protect against atherosclerosis by reducing foam cell formation through an autophagy-dependent pathway (67). Under oxLDL condition, macrophage foam cell formation is reduced by SIRT6 via induction of autophagy and cholesterol efflux. In particular, overexpression of SIRT6 in foam cells increased the levels of ABCA1 and ABCG1, activated cholesterol efflux, and reduced miR-33 levels. Indeed, transfection of miR-33 into cells overexpressing SIRT6 determined a reduced foam cell formation and reversed autophagy flux induction.

\section{SIRT1 and SIRT6 in Heart Disease}

SIRT1 and SIRT6 play diverse roles in the maintenance of heart function, with particular regard to protection against oxidative injury, I/R injury, and hypertrophic stimuli. In particular, SIRT1, well recognized to be implicated in the pathogenesis of heart failure and in the regulation of cardiac electrical activity $(49,130,186)$, has been proposed as a prognostic tool for myocardial infarction incidence.

In the heart, SIRT1 negatively regulates proapoptotic proteins Bax and positively regulates expression of the antiapoptotic protein B cell lymphoma-extra large (Bcl-xL) through FOXO activation. Importantly, SIRT1 exerts protective effect in the heart by specifically controlling acetylation and transcriptional activity of p53 in cardiomyocytes (118). In chronic type 1 diabetes model, reduced cardiac SIRT1 levels are linked to reduced levels of cardiac sarcoplasmic calcium ATPase (SERCA2a) (Fig. 6) (164). More recently, Prola et al. reported that SIRT1 protects cardiomyocytes from endoplasmic reticulum (ER) stress through physical interaction and deacetylation of eukaryotic translation initiation factor $2 \alpha$ (eIF2 $\alpha$ ) on Lys-141 (K141) and Lys- 


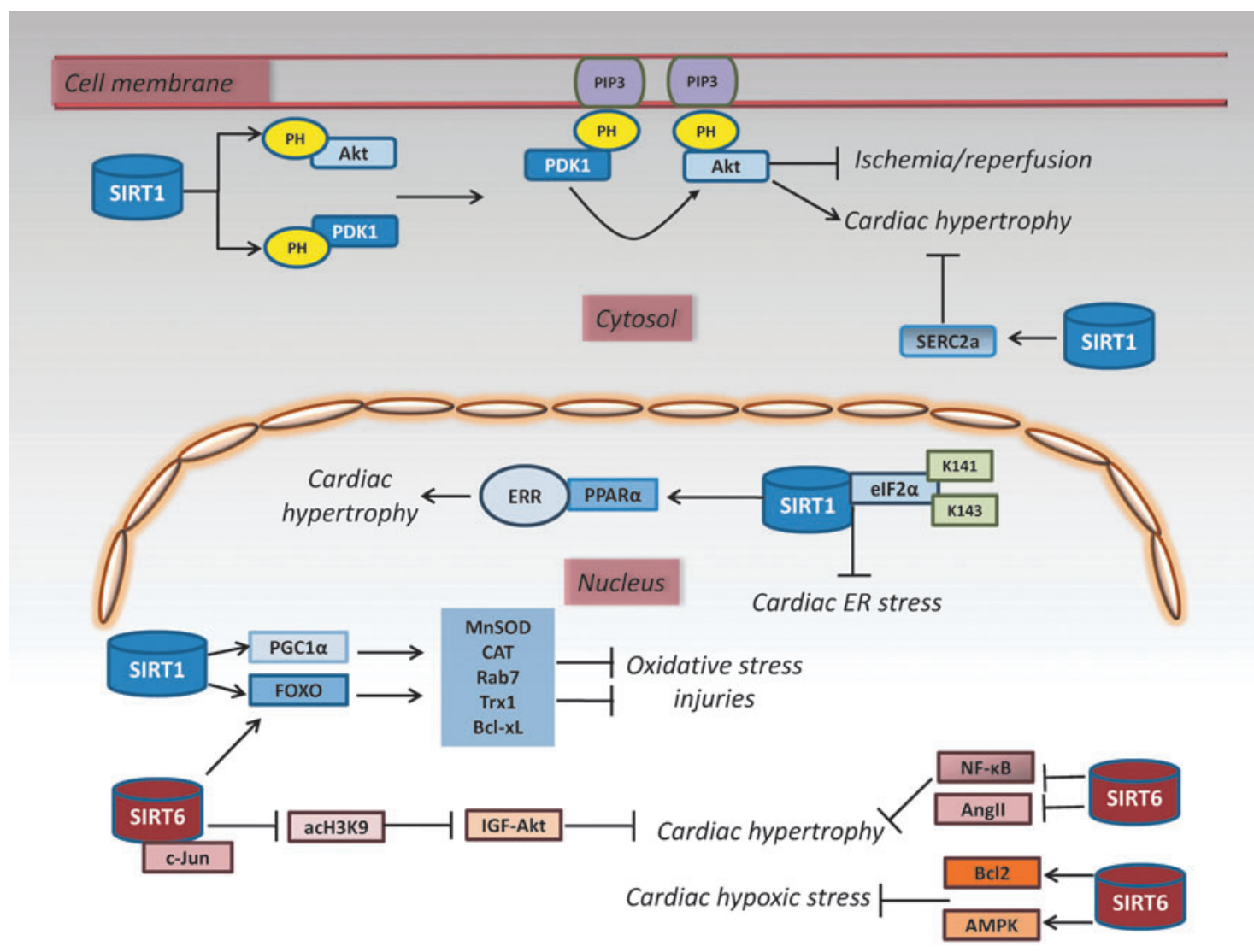

FIG. 6. SIRT1 and SIRT6 signaling networks in the heart protection. The diverse roles of SIRT1 and SIRT6 in the heart include protective effects against cardiac hypertrophy, I/R injury, oxidative stress injury, hearth failure, and autophagy. SIRT1 acts by deacetylating NF- $\kappa \mathrm{B}, \mathrm{FOXO}$, and Akt. Similarly, SIRT1 protects cardiomyocytes from endoplasmic reticulum stress by deacetylating eIF2 $\alpha$ on Lys-141 (K141) and Lys-143 (K143) residues. SIRT6-FOXO3 complex enhances the transcription of antioxidant genes, MnSOD and CAT. SIRT6 protects against hypoxic stress by activating AMPK, upregulating $\mathrm{Bcl} 2$, and suppressing the activity of NF- $\kappa \mathrm{B}$. SIRT6 blocks IGF-Akt signaling by targeting c-Jun and deacetylating histone type 3 (H3) acetylated Lys-9 (acH3K9). $\rightarrow$, positive regulation; - , negative regulation. Bcl-2, B-cell lymphoma 2; eIF2 $\alpha$, eukaryotic translation initiation factor $2 \alpha$; IGF, insulin-like growth factor; I/R, ischemia-reperfusion.

143 (K143) residues (Fig. 6) (148). Moreover, SIRT1 represents the downstream target of Lin28a in the protection against myocardial infarction injury (63). In contrast, inhibition of SIRT1 induces nuclear fragmentation and cleavage of caspase-3 and SIRT1-deficient mice exhibited abnormal heart development and prenatal lethality (4, 38). SIRT6 plays beneficial roles in heart failure and in the control of cardiac fibrosis, a pathological condition critical in the development of heart failure $(166,176)$. Indeed, SIRT6 negatively regulates cardiac fibroblast differentiation into myofibroblasts and its depletion increases cardiac fibroblast proliferation and extracellular matrix deposition, and upregulates focal adhesion-related genes and fibrosis-related genes through NF- $\kappa \mathrm{B}$ signaling (176).

\section{Oxidative and $I / R$ injuries}

SIRT1 responds differently to diverse cardiac stresses, as the expression of this protein is upregulated during pressure overload, nutrient starvation, exercise, and acute ischemic preconditioning, whereas it is downregulated during I/R injury (118). SIRT1 protects cardiomyocytes from oxidative stress-mediated damage through CAT and MnSOD activa- tion via deacetylation and activation of PGC- $1 \alpha$ and FOXO (4, 70) (Fig. 6).

SIRT1 expression decreases in the heart after I/R, whereas SIRT1 cardiac-specific overexpression improves functional recovery after I/R via upregulation of MnSOD, thioredoxin-1 (Trx1), and Bcl-xL, and downregulation of proapoptotic Bax (70). Activation of SIRT1 by resveratrol attenuates cardiac I/R injury by increasing ERK phosphorylation and reducing p38 and JNK expression levels (19). Furthermore, exogenous application of nicotinamide mononucleotide protects heart from I/R by mimicking the cardioprotective effect of ischemic preconditioning and overexpression of NAMPT, thereby protecting through an SIRT1-dependent mechanism (202). In contrast, in cardiac myocytes, the autophagic flux is impaired by NAMPT downregulation, probably acting in concert with SIRT1 signaling pathway (69).

However, the cardiac effect of SIRT1 against oxidative stress in the heart is concentration dependent. In fact, at baseline, high levels of SIRT1 expression in mice heart conversely induce oxidative stress through dysregulation of mitochondrial function (4). Hearts of male Wistar-Kyoto rats subjected to I/R showed increased cardiomyocyte apoptosis, caspase 3 cleavage, transient upregulation of SIRT1, 
increased FOXO1 expression and binding to SIRT1 promoter region, downregulation of SIRT6 expression, and AMPKdependent reduction of $\mathrm{NAD}^{+}$content, depicting a complex molecular network in the protection of heart during $\mathrm{I} / \mathrm{R}$ (Fig. 6) (30). Moreover, in diabetic mice, the resveratrolenhanced autophagic flux has been shown to ameliorate myocardial oxidative stress injury via SIRT1/FOXO1/Rab7 (190).

The protection exerted by SIRT6 against cardiac I/R involves the activation of FOXO3 in an AMPK-dependent manner followed by the formation of a complex with FOXO3 in the nucleus. Like SIRT1, SIRT6-FOXO3 complex enhances the transcription of FOXO-dependent antioxidant genes ( $M n S O D$ and $C A T$ ) to counteract the damage provoked by I/R (Fig. 6) (192). Furthermore, SIRT6 overexpression protects cardiomyocytes against hypoxic stress by activating AMPK, upregulating Bcl2, suppressing the activity of NF$\kappa \mathrm{B}$, and decreasing cellular ROS levels (Fig. 6) (114). SIRT6 directly binds to PARP1 and increases its poly-ADPribosylase activity, thereby stimulating double-strand break repair under oxidative stress (115). Since excessive PARP1 activation depletes $\mathrm{NAD}^{+}$levels in cardiomyocytes, it can be important to restrict overactivation of SIRT6 in the heart to optimize its cardioprotective effects.

Finally, SIRT6 also protects against hypoxia/reoxygenationinduced injury by attenuating hypoxia-induced apoptosis and mitochondrial defects via downregulation and translocation of p65 subunity of NF- $\kappa \mathrm{B}$ (39).

\section{Cardiac hypertrophy}

Both SIRT1 and SIR6 protect against cardiac hypertrophy, although SIRT1 also shows opposite effects depending on the interaction with other factors and severity of the stress $(4,5$, 134). Pressure overload in the heart induces cardiac hypertrophy and failure via upregulation of PPAR- $\alpha$-SIRT1 complex, suppressing the estrogen-related receptors (ERRs) transcriptional pathway (Fig. 6) (134). In addition, SIRT1dependent Akt activation exacerbates cardiac hypertrophy. Specifically, SIRT1-mediated deacetylation of both pleckstrin homology $(\mathrm{PH})$ domain of Akt and its upstream kinase PDK1 facilitates their interaction with phosphatidylinositol $(3,4,5)$ trisphosphate (PIP3) in the plasma membrane, where PDK1 phosphorylates and activates Akt, causing cardiac hypertrophy (165). SIRT1-deficient hearts show a reduced Akt activation and lower development of cardiac hypertrophy in response to physical exercise and Ang II stimulation (Fig. 6) (165).

In neonatal rat cardiomyocytes, SIRT6-dependent inhibition of NF- $\kappa \mathrm{B}$ suppresses cardiomyocyte hypertrophy, and overexpression of wild-type SIRT6 attenuates the Ang IIinduced cardiac hypertrophy $(24,209)$. Interestingly, the overexpression of nicotinamide mononucleotide adenylyl transferase 2 (Nmnat2) blocked the Ang II-induced cardiac hypertrophy, which was dependent on the activation of SIRT6 through the maintenance of intracellular $\mathrm{NAD}^{+}$levels. Among all sirtuins, increased levels of mRNA in response to Ang II stimulation were observed for SIRT6 and SIRT1 with a predominant role of SIRT6, as confirmed in cardiomyocyte model overexpressing Nmnat2, showing increased hypertrophic response when SIRT6 but not SIRT1 was knocked down (Fig. 6) (24). Accordingly, a novel PARP1 inhibitor,
AG-690/11026014, a compound able to prevent the Ang IIinduced cardiomyocyte hypertrophy, reverses the depletion of cellular $\mathrm{NAD}^{+}$and SIRT6 deacetylase activity (108). Importantly, under normal conditions, SIRT6 inhibits the expression of IGF signaling-related genes responsible for cardiac failure by deacetylating $\mathrm{H} 3$ at Lys-9 (H3K9) and repressing c-Jun activity (Fig. 6) (166). Contrarily, reduction of cardiac SIRT6 expression under pathological stress leading to the development of cardiac hypertrophy, fibrosis, and heart failure is linked to increased acetylation of $\mathrm{H} 3 \mathrm{~K} 9$ at the promoters of IGF signaling genes and c-Jun-mediated transcriptional activation.

Attenuation of Akt signaling via SIRT6-dependent FOXO3 activation also contributes to the proautophagic effect of SIRT6 in the suppression of isoproterenol-induced cardiac hypertrophy (Fig. 6) (111). More recently, the protective role of SIRT6 against cardiomyocyte hypertrophy was supported by the observation that the suppression of signal transducer and activator of transcription 3 (STAT3), critical for the development of cardiac hypertrophy and heart failure, takes part in the signaling that mediates the protective effect of SIRT6 (215).

\section{SIRT1 and SIRT6 Pharmacological Modulators in the Preclinical and Clinical Settings}

To date, an intensive research has been focused on the modulation of SIRT1 and SIRT6 with pharmacological and natural dietary compounds, as well as miRs $(37,42,75,118$, $152,188,195)$. Activation of SIRT1 by resveratrol derivatives, such as BTM-0512, shows a beneficial effect on highglucose-induced EC dysfunction (210). According to these results, 8-week-old male $\mathrm{C} 57 \mathrm{BL} / 6$ mice treated with resveratrol showed alleviated high-calorie diet-induced insulin resistance and ER stress by increasing SIRT1 expression, and by reversing expression of adipokines in varying degrees in both subcutaneous and visceral adipose tissues. Another compound, icariin, an important active component in Herba Epimedii, also acts as an activator of SIRT6 and inhibitor of NF- $\kappa \mathrm{B}$, showing to be potentially effective in treating CVD (36).

As widely reviewed $(42,152,188)$, a consistent number of ongoing or completed clinical trials (http://clinicaltrials.gov) are underway to investigate the safety, efficacy, pharmacodynamics, and pharmacokinetics of natural and synthetic compounds able to modulate SIRT1 and SIRT6 in several diseases, including CVD, inflammation, metabolic syndrome, insulin resistance, type 2 diabetes, and obesity. In this regard, clinical evaluation of SIRT1 pharmacological activator, SRT1720, SRT3025, SRT2104, and SRT501, resulted in prevented metabolic diseases, decreased atherosclerotic plaque formation, ameliorated lipid profile of cigarette smokers, and improved glucose tolerance in type 2 diabetic patients $(14,68,105,125,126,184)$.

In addition, results from a double-blind placebo-controlled study in patients with carotid artery atherosclerosis indicated that metformin treatment attenuated the proinflammation state in peripheral blood mononuclear cells through SIRT1 induction, p65 acetylation reduction, and NF- $\kappa$ B blockade (201).

Yet, the control of SIRT1 and SIRT6 activities in the CVD protection by specific activator/inhibitor remains a challenge and, despite the progresses made on SIRT1, clinical 
evaluations regarding SIRT6 are still limited. In particular, clinical outcomes on the efficacy of SIRT1 modulators have often been contradictory, probably because of the interaction of activators with multiple cellular targets and to a limited cross-validation of the findings. However, research on sirtuinmodulating compounds is still intensive, and specific hydrophobic motifs found in SIRT1 substrates, such as FOXO3a and PGC- $1 \alpha$, seem to facilitate SIRT1 activation by sirtuinactivating compounds (STACs) acting through a mechanism of direct "assisted allosteric activation" mediated by an $\mathrm{N}$-terminal activation domain in SIRT1 $(74,75,148)$.

Moreover, recently, a synthetic sulfonylurea compound (G004) showed beneficial effects on $\mathrm{ApoE}^{-/-}$mice against hyperglycemia and atherosclerosis by acting on SIRT1/ eNOS axis (149), and a novel PARP1 inhibitor AG-690/ 11026014 showed protective effects on Ang II-induced mouse cardiac remodeling by restoring the activity of SIRT1 in heart tissues (54).

In contrast, SIRT1, a redox-sensitive enzyme, could also be susceptible to regulation by redox-modulating agents, allowing the control of its post-translational modifications or the maintenance of the cellular redox environment, especially when extreme oxidative stress conditions occur. In this regard, among the natural dietary compounds able to modulate SIRT1 and SIRT6, ergothioneine, the 2-mercapto-L-histidine betaine, has been shown to prevent the high-glucose-induced endothelial senescence through modulation of SIRT1/p66 $6^{\text {shc }}$ and SIRT6/NF- $\kappa$ B pathways $(41,156,157)$.

Finally, a recently identified SIRT6 inhibitor, compound 1, tested in a mouse model of type 2 diabetes, resulted in reduced insulin, TGs, and cholesterol levels in plasma and improved the glycemic control by increasing the expression of the glucose transporters GLUT1 and GLUT4 in the muscle and enhancing the activity of the glycolytic pathway (160).

\section{Conclusions and Future Directions}

In the past few years, the key role of SIRT1 and SIRT6 signaling pathways in the protection against CVD has emerged. Their beneficial effects on inflammation, vascular aging, control of glucose homeostasis, atherosclerosis, and heart diseases are under intensive research and continuously unveiling novel targets within complex networks.

In this regard, relevant advances concerning SIRT1 and SIRT6 signaling in CVD protection are related to:

- the dependence of SIRT1 and SIRT6 activity by the cellular redox state, indicating that antioxidant compounds exhibit strong potential for the CVD protection acting on the SIRT1/FOXOs, SIRT1/NF- $\kappa \mathrm{B}$ axis, SIRT1/p66 ${ }^{\text {Shc }}$, and SIRT6/NF- $\kappa$ B axis.

- the in vivo antiatherogenic role of SIRT6, which makes this sirtuin a potential new target in preventing atherosclerosis.

- the efficacy of synthetic SIRT1 activators with good tolerability and bioavailability in humans, which overcome the limit of the low bioavailability of resveratrol.

- the overlap of regulatory mechanisms involving transcription factors and miR, such as NF- $\kappa$ B and miR-34a, indicating a regulatory interplay between these sirtuins.

Overall, among mechanisms controlled by these sirtuins, the recent evidence linking SIRT6 to atherosclerotic plaque development and vulnerability via $\mathrm{NF}-\kappa \mathrm{B} / \mathrm{NKG} 2 \mathrm{D}$ suggests that control of inflammatory pathways in CVD is particularly relevant for SIRT1 and SIRT6. At the same time, equally relevant is the cellular mechanism(s) affecting the intracellular glutathione levels under oxidative stress conditions, which seems to be critical in the control of both SIRT1 and SIRT6 activities.

Although these sirtuins control mechanisms responsible for the longevity and stability of the genome, making them attractive for the beneficial role in the context of age-associated diseases, the cross-talks between SIRT1 and SIRT6 signalings highlight the need to understand the totality of their molecular targets to achieve a highly specific and selective modulation at the cardiovascular level. As shown in this review, discussing simultaneously SIRT1 and SIRT6 signalings in CVD protection, the presence of common molecular targets suggests that these sirtuins might act synergistically.

Uncovering the full path of SIRT1 and SIRT6 signalings, including their possible links, in the cellular mechanisms of vascular aging and CVD, remains the key challenge in this field, along with a deeper understanding of the redox regulation of these sirtuins. In this regard, a consistent strength to future investigations will come from the expected mapping of the epigenome in human disease, offering the possibility to identify epigenetic targets specific for disease and disease stage.

Overall, the setting of specific SIRT1 and SIRT6 pharmacological modulators should be pursued with watchfulness for potential chronic effects of sirtuin activation, without excluding that interventions with dietary antioxidant compounds and healthy lifestyle choice, including moderate physical exercise and calorie restriction, can be crucial tools for a time control of the cellular oxidative stress conditions driving to vascular aging and CVD.

\section{Acknowledgments}

Work in our laboratory is supported by the PON I\&C 201420-Horizon 2020-RAZIONALE (no. 129). The authors apologize to investigators whose work was not cited because of space limitations.

\section{References}

1. Aditya R, Kiran AR, Varma DS, Vemuri R, and Gundamaraju R. A review on SIRtuins in diabetes. Curr Pharm Des 2017 [Epub ahead of print]; DOI: 10.2174/ 1381612823666170125153334.

2. Akhmedov A, Camici GG, Reiner MF, Bonetti N, Costantino S, Holy EW, Spescha RD, Stivala S, Schaub Clerigué A, Speer T, Breitenstein A, Manz J, Lohmann C, Paneni F, Beer JH, and Lüscher TF. Endothelial LOX-1 activation differentially regulates arterial thrombus formation depending on oxLDL Levels: role of the Oct-1/ SIRT1 and ERK1/2 pathways. Cardiovasc Res 113: 498507, 2017.

3. Albiero M, Poncina N, Tjwa M, Ciciliot S, Menegazzo L, Ceolotto G, Vigili de Kreutzenberg S, Moura R, Giorgio M, Pelicci P, Avogaro A, and Fadini GP. Diabetes causes bone marrow autonomic neuropathy and impairs stem cell mobilization via dysregulated p66Shc and Sirt1. Diabetes 4: 1353-1365, 2014.

4. Alcendor RR, Gao S, Zhai P, Zablocki D, Holle E, Yu X, Tian B, Wagner T, Vatner SF, and Sadoshima J. Sirt1 
regulates aging and resistance to oxidative stress in the heart. Circ Res 100: 1512-1521, 2007.

5. Alcendor RR, Kirshenbaum LA, Imai S, Vatner SF, and Sadoshima J. Silent information regulator 2alpha, a longevity factor and class III histone deacetylase, is an essential endogenous apoptosis inhibitor incardiac myocytes. Circ Res 95: 971-980, 2004.

6. Anderson JG, Ramadori G, Ioris RM, Galiè M, Berglund ED, Coate KC, Fujikawa T, Pucciarelli S, Moreschini B, Amici A, Andreani C, and Coppari R. Enhanced insulin sensitivity in skeletal muscle and liver by physiological overexpression of SIRT6. Mol Metab 4: 846-856, 2015.

7. Antoniades C, Shirodaria C, Warrick N, Cai S, de Bono J, Lee J, Leeson P, Neubauer S, Ratnatunga C, Pillai R, Refsum H, and Channon KM. 5-methyltetrahydrofolate rapidly improves endothelial function and decreases superoxide production in human vessels: effects on vascular tetrahydrobiopterin availability and endothelial nitric oxide synthase coupling. Circulation 114: 1193-1201, 2006.

8. Arunachalam G, Sundar IK, Hwang JW, Yao H, and Rahman I. Emphysema is associated with increased inflammation in lungs of atherosclerosis-prone mice by cigarette smoke: implications in comorbidities of COPD. $J$ Inflamm (Lond) 7: 34, 2010.

9. Arunachalam G, Yao H, Sundar IK, Caito S, and Rahman I. SIRT1 regulates oxidant- and cigarette smoke-induced eNOS acetylation in endothelial cells: role of resveratrol. Biochem Biophys Res Commun 393: 66-72, 2010.

10. Badi I, Burba I, Ruggeri C, Zeni F, Bertolotti M, Scopece A, Pompilio G, and Raucci A. MicroRNA-34a induces vascular smooth muscle cells senescence by SIRT1 downregulation and promotes the expression of ageassociated pro-inflammatory secretory factors. J Gerontol A Biol Sci Med Sci 70: 1304-1311, 2015.

11. Bagul PK, Deepthi N, Sultana R, and Banerjee SK. Resveratrol ameliorates cardiac oxidative stress in diabetes through deacetylation of NF-kB-p65 and histone 3. J Nutr Biochem 26: 1298-1307, 2015.

12. Bai B, Liang Y, Xu C, Lee MY, Xu A, Wu D, Vanhoutte $\mathrm{PM}$, and Wang Y. Cyclin-dependent kinase 5-mediated hyperphosphorylation of sirtuin-1 contributes to the development of endothelial senescence and atherosclerosis. Circulation 126: 729-740, 2012.

13. Bai B, Man AW, Yang K, Guo Y, Xu C, Tse HF, Han W, Bloksgaard M, De Mey JG, Vanhoutte PM, Xu A, and Wang Y. Endothelial SIRT1 prevents adverse arterial remodeling by facilitating HERC2-mediated degradation of acetylated LKB1. Oncotarget 7: 39065-39081, 2016.

14. Baksi A, Kraydashenko O, Zalevkaya A, Stets R, Elliott P, Haddad J, Hoffmann E, Vlasuk GP, and Jacobson EW. A phase II, randomized, placebo controlled, double-blind, multi-dose study of SRT2104, a SIRT1 activator, in subjects with type 2 diabetes. Br J Clin Pharmacol 78: 69-77, 2014.

15. Balestrieri ML, Rienzo M, Felice F, Rossiello R, Grimaldi V, Milone L, Casamassimi A, Servillo L, Farzati B, Giovane A, and Napoli C. High glucose downregulates endothelial progenitor cell number via SIRT1. Biochim Biophys Acta 1784: 936-945, 2008.

16. Balestrieri ML, Rizzo MR, Barbieri M, Paolisso P, D'Onofrio N, Giovane A, Siniscalchi M, Minicucci F, Sardu C, D'Andrea D, Mauro C, Ferraraccio F, Servillo L, Chirico F, Caiazzo P, Paolisso G, and Marfella R. Sirtuin 6 expression and inflammatory activity in diabetic ath- erosclerotic plaques: effects of incretin treatment. Diabetes 64: 1395-1406, 2015.

17. Balestrieri ML, Servillo L, Esposito A, D’Onofrio N, Giovane A, Casale R, Barbieri M, Paolisso P, Rizzo MR, Paolisso G, and Marfella R. Poor glycaemic control in type 2 diabetes patients reduces endothelial progenitor cell number by influencing SIRT1 signalling via plateletactivating factor receptor activation. Diabetologia 56: 162-172, 2013.

18. Bao X, Wang Y, Li X, Li XM, Liu Z, Yang T, Wong CF, Zhang J, Hao Q, and Li XD. Identification of 'erasers' for lysine crotonylated histone marks using a chemical proteomics approach. Elife 4: 3, 2014.

19. Becatti M, Taddei N, Cecchi C, Nassi N, Nassi PA, and Fiorillo C. SIRT1 modulates MAPK pathways in ischemic-reperfused cardiomyocytes. Cell Mol Life Sci 69: 2245-2260, 2012.

20. Bindu S, Pillai VB, and Gupta MP. Role of sirtuins in regulating pathophysiology of the heart. Trends Endocrinol Metab 27: 563-573, 2016.

21. Bonomini F, Tengattini S, Fabiano A, Bianchi R, and Rezzani R. Atherosclerosis and oxidative stress. Histol Histopathol 23: 381-390, 2008.

22. Borradaile NM and Pickering JG. Nicotinamide phosphoribosyltransferase imparts human endothelial cells with extended replicative lifespan and enhanced angiogenic capacity in a high glucose environment. Aging Cell 8: 100-112, 2009.

23. Brunet A, Sweeney LB, Sturgill JF, Chua KF, Greer PL, Lin Y, Tran H, Ross SE, Mostoslavsky R, Cohen HY, Hu LS, Cheng HL, Jedrychowski MP, Gygi SP, Sinclair DA, Alt FW, and Greenberg ME. Stress-dependent regulation of FOXO transcription factors by the SIRT1 deacetylase. Science 303: 2011-2015, 2004.

24. Cai Y, Yu SS, Chen SR, Pi RB, Gao S, Li H, Ye JT, and Liu PQ. Nmnat2 protects cardiomyocytes from hypertrophy via activation of SIRT6. FEBS Lett 586: 866-874, 2012.

25. Caito S, Rajendrasozhan S, Cook S, Chung S, Yao H, Friedman AE, Brookes PS, and Rahman I. SIRT1 is a redox-sensitive deacetylase that is post-translationally modified by oxidants and carbonyl stress. FASEB $J$ 24: 3145-3159, 2010.

26. Camici GG, Cosentino F, Tanner FC, and Lüscher TF. The role of p66Shc deletion in age-associated arterial dysfunction and disease states. J Appl Physiol (1985) 105: 1628-1631, 2008.

27. Cardellini M, Menghini R, Martelli E, Casagrande V, Marino A, Rizza S, Porzio O, Mauriello A, Solini A, Ippoliti A, Lauro R, Folli F, and Federici M. TIMP3 is reduced in atherosclerotic plaques from subjects with type 2 diabetes and increased by SirT1. Diabetes 58: 23962401, 2009.

28. Cardus A, Uryga AK, Walters G, and Erusalimsky JD. SIRT6 protects human endothelial cells from DNA damage, telomere dysfunction, and senescence. Cardiovasc Res 97: 571-579, 2013.

29. Carlomosti F, D’Agostino M, Beji S, Torcinaro A, Rizzi R, Zaccagnini G, Maimone B, Di Stefano V, De Santa F, Cordisco S, Antonini A, Ciarapica R, Dellambra E, Martelli F, Avitabile D, Capogrossi MC, and Magenta A. Oxidative stress-induced miR-200c disrupts the regulatory loop among SIRT1, FOXO1, and eNOS. Antioxid Redox Signal 27: 328-344, 2017. 
30. Cattelan A, Ceolotto G, Bova S, Albiero M, Kuppusamy M, De Martin S, Semplicini A, Fadini GP, de Kreutzenberg SV, and Avogaro A. NAD(+)-dependent SIRT1 deactivation has a key role on ischemia-reperfusion-induced apoptosis. Vasc Pharmacol 70: 35-44, 2015.

31. Ceolotto G, De Kreutzenberg SV, Cattelan A, Fabricio AS, Squarcina E, Gion M, Semplicini A, Fadini GP, and Avogaro A. Sirtuin 1 stabilization by HuR represses TNF- $\alpha-$ and glucose-induced E-selectin release and endothelial cell adhesiveness in vitro: relevance to human metabolic syndrome. Clin Sci (Lond) 127: 449-461, 2014.

32. Charles S, Raj V, Arokiaraj J, and Mala K. Caveolin1/ protein arginine methyltransferase $1 / \operatorname{sirtuin} 1$ axis as a potential target against endothelial dysfunction. Pharmacol Res 119: 1-11, 2017.

33. Chen HZ, Wan YZ, and Liu DP. Cross-talk between SIRT1 and p66Shc in vascular diseases. Trends Cardiovasc Med 23: 237-241, 2013.

34. Chen ML, Yi L, Jin X, Liang XY, Zhou Y, Zhang T, Xie Q, Zhou X, Chang H, Fu YJ, Zhu JD, Zhang QY, and Mi MT. Resveratrol attenuates vascular endothelial inflammation by inducing autophagy through the cAMP signaling pathway. Autophagy 9: 2033-2045, 2013.

35. Chen Y, Liu H, Zhang H, Liu E, Xu CB, and Su X. The sirt1/NF-kB signaling pathway is involved in regulation of endothelin type $\mathrm{B}$ receptors mediated by homocysteine in vascular smooth muscle cells. Biomed Pharmacother 84: 1979-1985, 2016.

36. Chen Y, Sun T, Wu J, Kalionis B, Zhang C, Yuan D, Huang J, Cai W, Fang H, and Xia S. Icariin intervenes in cardiac inflammaging through upregulation of SIRT6 enzyme activity and inhibition of the NF-kappa B pathway. Biomed Res Int 2015: 895976, 2015.

37. Chen Z, Shentu TP, Wen L, Johnson DA, and Shyy JY. Regulation of SIRT1 by oxidative stress-responsive miRNAs and a systematic approach to identify its role in the endothelium. Antioxid Redox Signal 19: 1522-1538, 2013.

38. Cheng HL, Mostoslavsky R, Saito S, Manis JP, Gu Y, Patel P, Bronson R, Appella E, Alt FW, and Chua KF. Developmental defects and p53 hyperacetylation in Sir2 homolog (SIRT1)-deficient mice. Proc Natl Acad Sci U S A 100: 10794-10799, 2003.

39. Cheng MY, Cheng YW, Yan J, Hu XQ, Zhang H, Wang ZR, Yin Q, and Cheng W. SIRT6 suppresses mitochondrial defects and cell death via the NF- $\kappa \mathrm{B}$ pathway in myocardial hypoxia/reoxygenation induced injury. Am J Transl Res 8: 5005-5015, 2016.

40. Costantino S, Paneni F, and Cosentino F. Ageing, metabolism and cardiovascular disease. J Physiol 594: 2061-2073, 2016.

41. D’Onofrio N, Servillo L, Giovane A, Casale R, Vitiello M, Marfella R, Paolisso G, and Balestrieri ML. Ergothioneine oxidation in the protection against high-glucose induced endothelial senescence: involvement of SIRT1 and SIRT6. Free Radic Biol Med 19: 211-222, 2016.

42. D'Onofrio N, Vitiello M, Casale R, Servillo L, Giovane A, and Balestrieri ML. Sirtuins in vascular diseases: emerging roles and therapeutic potential. Biochim Biophys Acta 7: 1311-1322, 2015.

43. de Kreutzenberg SV, Ceolotto G, Papparella I, Bortoluzzi A, Semplicini A, Dalla Man C, Cobelli C, Fadini GP, and Avogaro A. Downregulation of the longevity-associated protein sirtuin 1 in insulin resistance and metabolic syndrome: potential biochemical mechanisms. Diabetes 59: 1006-1015, 2010.
44. de Nigris F, Balestrieri ML, and Napoli C. Targeting cMyc, Ras and IGF cascade to treat cancer and vascular disorders. Cell Cycle 5: 1621-1628, 2006.

45. Di Lisa F, Giorgio M, Ferdinandy P, and Schulz R. New aspects of p66Shc in ischemia reperfusion injury and cardiovascular diseases. Br J Pharmacol 174: 1690-1703, 2017.

46. Ding M, Lei J, Han H, Li W, Qu Y, Fu E, Fu F, and Wang $X$. SIRT1 protects against myocardial ischemiareperfusion injury via activating eNOS in diabetic rats. Cardiovasc Diabetol 14: 143, 2015.

47. Dominy JE, Jr., Lee Y, Jedrychowski MP, Chim H, Jurczak MJ, Camporez JP, Ruan HB, Feldman J, Pierce K, Mostoslavsky R, Denu JM, Clish CB, Yang X, Shulman GI, Gygi SP, and Puigserver P. The deacetylase Sirt6 activates the acetyltransferase GCN5 and suppresses hepatic gluconeogenesis. Mol Cell 48: 900-913, 2012.

48. Donato AJ, Magerko KA, Lawson BR, Durrant JR, Lesniewski LA, and Seals DR. SIRT-1 and vascular endothelial dysfunction with ageing in mice and humans. $J$ Physiol 589: 4545-4554, 2011.

49. Doulamis IP, Tzani AI, Konstantopoulos PS, Samanidis G, Georgiopoulos G, Toutouzas KP, Perrea DN, and Perreas KG. A sirtuin 1/MMP2 prognostic index for myocardial infarction in patients with advanced coronary artery disease. Int J Cardiol 230: 447-453, 2017.

50. Downey M, Johnson JR, Davey NE, Newton BW, Johnson TL, Galaang S, Seller CA, Krogan N, and Toczyski DP. Acetylome profiling reveals overlap in the regulation of diverse processes by sirtuins, gen5, and esa1. Mol Cell Proteomics 14: 162-176, 2015.

51. El Assar M, Angulo J, and Rodríguez-Mañas L. Oxidative stress and vascular inflammation in aging. Free Radic Biol Med 65: 380-401, 2013.

52. Elahi MM, Kong YX, and Matata BM. Oxidative stress as a mediator of cardiovascular disease. Oxid Med Cell Longev 2: 259-269, 2009.

53. Elhanati S, Kanfi Y, Varvak A, Roichman A, CarmelGross I, Barth S, Gibor G, and Cohen HY. Multiple regulatory layers of SREBP1/2 by SIRT6. Cell Rep 4: 905-912, 2013.

54. Feng GS, Zhu CG, Li ZM, Wang PX, Huang Y, Liu M, He P, Lou LL, Chen SR, and Liu PQ. Synthesis of the novel PARP-1 inhibitor AG-690/11026014 and its protective effects on angiotensin II-induced mouse cardiac remodeling. Acta Pharmacol Sin 38: 638-650, 2017.

55. Galimov ER. The role of p66shc in oxidative stress and apoptosis. Acta Naturae 2: 44-51, 2010.

56. Gano LB, Donato AJ, Pasha HM, Hearon CM, Jr., Sindler AL, and Seals DR. The SIRT1 activator SRT1720 reverses vascular endothelial dysfunction, excessive superoxide production, and inflammation with aging in mice. Am J Physiol Heart Circ Physiol 307: H1754-H1763, 2014.

57. Gimbrone MA, Jr. and Garcia-Cardena G. Endothelial cell dysfunction and the pathobiology of atherosclerosis. Circ Res 118: 620-636, 2016.

58. Gorenne I, Kumar S, Gray K, Figg N, Yu H, Mercer J, and Bennett M. Vascular smooth muscle cell sirtuin 1 protects against DNA damage and inhibits atherosclerosis. Circulation 3: 386-396, 2013.

59. Griendling KK and FitzGerald GA. Oxidative stress and cardiovascular injury, part II: animal and human studies. Circulation 108: 2034-2040, 2003.

60. Guan D, Lim JH, Peng L, Liu Y, Lam M, Seto E, and Kao HY. Deacetylation of the tumor suppressor protein PML 
regulates hydrogen peroxide-induced cell death. Cell Death Dis 5: e1340, 2014.

61. Guo H, Chen Y, Liao L, and Wu W. Resveratrol protects HUVECs from oxidized-LDL induced oxidative damage by autophagy upregulation via the AMPK/SIRT1 pathway. Cardiovasc Drugs Ther 27: 189-198, 2013.

62. Haigis MC and Sinclair DA. Mammalian sirtuins: biological insights and disease relevance. Annu Rev Pathol 5: 253-295, 2010.

63. Hao Y, Lu Q, Yang G, and Ma A. Lin28a protects against postinfarction myocardial remodeling and dysfunction through Sirt1 activation and autophagy enhancement. Biochem Biophys Res Commun 479: 833-840, 2016.

64. Hara F, Tatebe J, Watanabe I, Yamazaki J, Ikeda T, and Morita T. Molecular hydrogen alleviates cellular senescence in endothelial cells. Circ J 80: 2037-2046, 2016.

65. Hashimoto-Komatsu A, Hirase T, Asaka M, and Node K. Angiotensin II induces microtubule reorganization mediated by a deacetylase SIRT2 in endothelial cells. Hypertens Res 34: 949-956, 2011.

66. Haskó $\mathrm{G}$ and Pacher P. Endothelial Nrf2 activation: a new target for resveratrol? Am J Physiol Heart Circ Physiol 299: H10-H12, 2010.

67. He J, Zhang G, Pang Q, Yu C, Xiong J, Zhu J, and Chen F. SIRT6 reduces macrophage foam cell formation by inducing autophagy and cholesterol efflux under ox-LDL condition. FEBS J 284: 1324-1337, 2017.

68. Hoffmann E, Wald J, Lavu S, Roberts J, Beaumont C, Haddad J, Elliott P, Westphal C, and Jacobson E. Pharmacokinetics and tolerability of SRT2104, a first-in-class small molecule activator of SIRT1, after single and repeated oral administration in man. Br J Clin Pharmacol 75: 186-196, 2013.

69. Hsu CP, Oka S, Shao D, Hariharan N, and Sadoshima J. Nicotinamide phosphoribosyltransferase regulates cell survival through NAD+ synthesis in cardiac myocytes. Circ Res 105: 481-491, 2009.

70. Hsu CP, Zhai P, Yamamoto T, Maejima Y, Matsushima S, Hariharan N, Shao D, Takagi H, Oka S, and Sadoshima J. Silent information regulator 1 protects the heart from ischemia/reperfusion. Circulation 122: 2170-2182, 2010.

71. Hu S, Liu H, Ha Y, X Luo, Motamedi M, Gupta MP, Ma JX, Tilton RG, and Zhang W. Posttranslational modification of Sirt6 activity by peroxynitrite. Free Radic Biol Med 79: 176-185, 2015.

72. Huang JY, Hirschey MD, Shimazu T, Ho L, and Verdin E. Mitochondrial sirtuins. Biochim Biophys Acta 1804: 1645-1651, 2010.

73. Huang K, Yan ZQ, Zhao D, Chen SG, Gao LZ, Zhang P, Shen BR, Han HC, Qi YX, and Jiang ZL. SIRT1 and FOXO mediate contractile differentiation of vascular smooth muscle cells under cyclic stretch. Cell Physiol Biochem 37: 1817-1829, 2015.

74. Hubbard BP, Gomes AP, Dai H, Li J, Case AW, Considine T, Riera TV, Lee JE, E SY, Lamming DW, Pentelute BL, Schuman ER, Stevens LA, Ling AJ, Armour SM, Michan S, Zhao H, Jiang Y, Sweitzer SM, Blum CA, Disch JS, Ng PY, Howitz KT, Rolo AP, Hamuro Y, Moss J, Perni RB, Ellis JL, Vlasuk GP, and Sinclair DA. Evidence for a common mechanism of SIRT1 regulation by allosteric activators. Science 339: 1216-1219, 2013.

75. Hubbard BP and Sinclair DA. Small molecule SIRT1 activators for the treatment of aging and age-related diseases. Trends Pharmacol Sci 35: 146-154, 2014.
76. Hung $\mathrm{CH}$, Chan $\mathrm{SH}$, Chu PM, and Tsai KL. Quercetin is a potent anti-atherosclerotic compound by activation of SIRT1 signaling under oxLDL stimulation. Mol Nutr Food Res 59: 1905-1917, 2015.

77. Huynh FK, Hershberger KA, and Hirschey MD. Targeting sirtuins for the treatment of diabetes. Diabetes Manag (Lond) 3: 245-257, 2013.

78. Hwang JW, Yao H, Caito S, Sundar IK, and Rahman I. Redox regulation of SIRT1 in inflammation and cellular senescence. Free Radic Biol Med 61: 95-110, 2013.

79. Ido Y. Diabetic complications within the context of aging: nicotinamide adenine dinucleotide redox, insulin C-peptide, sirtuin 1-liver kinase B1-adenosine monophosphateactivated protein kinase positive feedback and forkhead box O3. J Diabetes Investig 7: 448-458, 2016.

80. Jedrusik-Bode M, Studencka M, Smolka C, Baumann T, Schmidt H, Kampf J, Paap F, Martin S, Tazi J, Müller KM, Krüger M, Braun T, and Bober E. The sirtuin SIRT6 regulates stress granule formation in $C$. elegans and mammals. J Cell Sci 126: 5166-5177, 2013.

81. Jin X, Chen M, Yi L, Chang H, Zhang T, Wang L, Ma W, Peng X, Zhou Y, and Mi M. Delphinidin-3-glucoside protects human umbilical vein endothelial cells against oxidized low-density lipoprotein-induced injury by autophagy upregulation via the AMPK/SIRT1 signaling pathway. Mol Nutr Food Res 58: 1941-1951, 2014.

82. Jung SB, Kim CS, Kim YR, Naqvi A, Yamamori T, Kumar S, Kumar A, and Irani K. Redox factor-1 activates endothelial SIRTUIN1 through reduction of conserved cysteine sulfhydryls in its deacetylase domain. PLoS One 8: $65415,2013$.

83. Kanfi Y, Naiman S, Amir G, Peshti V, Zinman G, Nahum L, Bar-Joseph Z, and Cohen HY. The sirtuin SIRT6 regulates lifespan in male mice. Nature 483: 218-221, 2012.

84. Kao CL, Chen LK, Chang YL, Yung MC, Hsu CC, Chen YC, Lo WL, Chen SJ, Ku HH, and Hwang SJ. Resveratrol protects human endothelium from $\mathrm{H}(2) \mathrm{O}(2)$-induced oxidative stress and senescence via SirT1 activation. $J$ Atheroscler Thromb 17: 970-979, 2010.

85. Kato R, Mizuno S, Kadowaki M, Shiozaki K, Akai M, Nakagawa K, Oikawa T, Iguchi M, Osanai K, Ishizaki T, Voelkel NF, and Toga H. Sirt1 expression is associated with CD31 expression in blood cells from patients with chronic obstructive pulmonary disease. Respir Res 17: 139, 2016.

86. Kawahara TL, Michishita E, Adler AS, Damian M, Berber E, Lin M, McCord RA, Ongaigui KC, Boxer LD, Chang HY, and Chua KF. SIRT6 links histone H3 lysine 9 deacetylation to NF-kappaB-dependent gene expression and organismal life span. Cell 136: 62-74, 2009.

87. Kawai Y, Garduno L, Theodore M, Yang J, and Arinze IJ. Acetylation-deacetylation of the transcription factor Nrf2 (nuclear factor erythroid 2-related factor 2) regulates its transcriptional activity and nucleocytoplasmic localization. J Biol Chem 286: 7629-7640, 2011.

88. Kazantsev AG and Outeiro TF. Editorial on special topic: sirtuins in metabolism, aging, and disease. Front Pharmacol 3: 71, 2012.

89. Kemp JR and Longworth MS. Crossing the LINE toward genomic instability: LINE-1 retrotransposition in cancer. Front Chem 3: 68, 2015.

90. Kida Y and Goligorsky MS. Sirtuins, cell senescence, and vascular aging. Can J Cardiol 32: 634-641, 2016.

91. Kim HS, Xiao C, Wang RH, Lahusen T, Xu X, Vassilopoulos A, Vazquez-Ortiz G, Jeong WI, Park O, Ki SH, 
Gao B, and Deng CX. Hepatic-specific disruption of SIRT6 in mice results in fatty liver formation due to enhanced glycolysis and triglyceride synthesis. Cell Metab 12: 224-236, 2010.

92. Kitada M, Kume S, Takeda-Watanabe A, Tsuda S, Kanasaki K, and Koya D. Calorie restriction in overweight males ameliorates obesity-related metabolic alterations and cellular adaptations through antiaging effects, possibly including AMPK and SIRT1 activation. Biochim Biophys Acta 1830: 4820-4827, 2013.

93. Kitada M, Ogura Y, and Koya D. The protective role of Sirt1 in vascular tissue: its relationship to vascular aging and atherosclerosis. Aging (Albany NY) 8: 2290-2307, 2016.

94. Kong D, Zhan Y, Liu Z, Ding T, Li M, Yu H, Zhang L, Li $\mathrm{H}$, Luo A, Zhang D, Wang Y, Wang S, Zhang Z, Zhang H, Huang X, Yao P, Ding Y, and Liu Z. SIRT1-mediated $\mathrm{ER} \beta$ suppression in the endothelium contributes to vascular aging. Aging Cell 2016 [Epub ahead of print]; DOI: 10.1111/acel.12515.

95. Kong X, Guan J, Li J, Wei J, and Wang R. P66Shc-SIRT1 regulation of oxidative stress protects against cardiocerebral vascular disease. Mol Neurobiol 2016 [Epub ahead of print]; DOI: 10.1007/s12035-016-0073-2.

96. Kumar S and Lombard DB. Mitochondrial sirtuins and their relationships with metabolic disease and cancer. Antioxid Redox Signal 22: 1060-1077, 2015.

97. Lappas M. Anti-inflammatory properties of sirtuin 6 in human umbilical vein endothelial cells. Mediators Inflamm 2012: 597514, 2012.

98. Lemarie CA, Shbat L, Marchesi C, Angulo OJ, Deschenes ME, Blostein MD, Paradis P, and Schiffrin EL. Mthfr deficiency induces endothelial progenitor cell senescence via uncoupling of eNOS and downregulation of SIRT1. Am J Physiol Heart Circ Physiol 300: 745-753, 2011.

99. Lerrer B, Gertler AA, and Cohen HY. The complex role of SIRT6 in carcinogenesis. Carcinogenesis 37: 108-118, 2016.

100. Li L, Zhang HN, Chen HZ, Gao P, Zhu LH, Li HL, Lv X, Zhang QJ, Zhang R, Wang Z, She ZG, Zhang R, Wei YS, Du GH, Liu DP, and Liang CC. SIRT1 acts as a modulator of neointima formation following vascular injury in mice. Circ Res 108: 1180-1189, 2011.

101. Li Q, Kim YR, Vikram A, Kumar S, Kassan M, Gabani M, Lee SK, Jacobs JS, and Irani K. P66Shc-induced microRNA-34a causes diabetic endothelial dysfunction by downregulating Sirtuin1. Arterioscler Thromb Vasc Biol 36: 2394-2403, 2016.

102. Li X, Zhang S, Blander G, Tse JG, Krieger M, and Guarente L. SIRT1 deacetylates and positively regulates the nuclear receptor LXR. Mol Cell 28: 91-106, 2007.

103. Liao CY and Kennedy BK. SIRT6, oxidative stress, and aging. Cell Res 26: 143-144, 2016.

104. Libby P, Bornfeldt KE, and Tall AR. Atherosclerosis: successes, surprises, and future challenges. Circ Res 118: 531-534, 2016.

105. Libri V, Brown AP, Gambarota G, Haddad J, Shields GS, Dawes H, Pinato DJ, Hoffman E, Elliot PJ, Vlasuk GP, Jacobson E, Wilkins MR, and Matthews PM. A pilot randomized, placebo controlled, double blind phase I trial of the novel SIRT1 activator SRT2104 in elderly volunteers. PLoS One 7: e51395, 2012.

106. Lin XL, Liu Y, Liu M, Hu H, Pan Y, Fan XJ, Hu XM, and Zou WW. Inhibition of hydrogen peroxide-induced human umbilical vein endothelial cells aging by allicin de- pends on Sirtuin1 activation. Med Sci Monit 23: 563-570, 2017.

107. Ling L, Gu S, and Cheng Y. Resveratrol inhibits adventitial fibroblast proliferation and induces cell apoptosis through the SIRT1 pathway. Mol Med Rep 15: 567-572, 2017.

108. Liu M, Li Z, Chen GW, Li ZM, Wang LP, Ye JT, Luo HB, and Liu PQ. AG-690/11026014, a novel PARP-1 inhibitor, protects cardiomyocytes from AngII-induced hypertrophy. Mol Cell Endocrinol 392: 14-22, 2014.

109. Liu R, Liu H, Ha Y, Tilton RG, and Zhang W. Oxidative stress induces endothelial cell senescence via downregulation of Sirt6. Biomed Res Int 2014: 902842, 2014.

110. Liu Z, Wang J, Huang X, Li Z, and Liu P. Deletion of sirtuin 6 accelerates endothelial dysfunction and atherosclerosis in apolipoprotein E-deficient mice. Transl Res 172: 18-29, 2016.

111. Lu J, Sun D, Liu Z, Li M, Hong H, Liu C, Gao S, Li H, Cai Y, Chen S, Li Z, Ye J, and Liu P. SIRT6 suppresses isoproterenol-induced cardiac hypertrophy through activation of autophagy. Transl Res 172: 96-112, 2016.

112. Luo J, Nikolaev AY, Imai S, Chen D, Su F, Shiloh A, Guarente L, and Gu W. Negative control of p53 by Sir2alpha promotes cell survival under stress. Cell 107: 137-148, 2001.

113. Ma L, Liu X, Zhao Y, Chen B, Li X, and Qi R. Ginkgolide $B$ reduces LOX-1 expression by inhibiting Akt phosphorylation and increasing Sirt1 expression in oxidized LDL-stimulated human umbilical vein endothelial cells. PLoS One 8: e74769, 2013.

114. Maksin-Matveev A, Kanfi Y, Hochhauser E, Isak A, Cohen HY, and Shainberg A. Sirtuin 6 protects the heart from hypoxic damage. Exp Cell Res 330: 81-90, 2015.

115. Mao Z, Hine C, Tian X, Van Meter M, Au M, Vaidya A, Seluanov A, and Gorbunova V. SIRT6 promotes DNA repair under stress by activating PARP1. Science 332: 1443-1446, 2011.

116. Marfella R, Rizzo MR, Siniscalchi M, Paolisso P, Barbieri M, Sardu C, Savinelli A, Angelico N, Del Gaudio S, Esposito N, Rambaldi PF, D’Onofrio N, Mansi L, Mauro C, Paolisso G, and Balestrieri ML. Peri-procedural tight glycemic control during early percutaneous coronary intervention up-regulates endothelial progenitor cell level and differentiation during acute ST-elevation myocardial infarction: effects on myocardial salvage. Int J Cardiol 168: 3954-3962, 2013.

117. Martínez-Redondo $\mathrm{P}$ and Vaquero A. The diversity of histone versus nonhistone sirtuin substrates. Genes Cancer 4: 148-163, 2013.

118. Matsushima $S$ and Sadoshima J. The role of sirtuins in cardiac disease. Am J Physiol Heart Circ Physiol 309: H1375-H1389, 2015.

119. Mattagajasingh I, Kim CS, Naqvi A, Yamamori T, Hoffman TA, Jung SB, De Ricco J, Kasuno K, and Irani K. SIRT1 promotes endothelium-dependent vascular relaxation by activating endothelial nitric oxide synthase. Proc Natl Acad Sci U S A 104: 14855-14860, 2007.

120. Menghini R, Casagrande V, Cardellini M, Martelli E, Terrinoni A, Amati F, Vasa-Nicotera M, Ippoliti A, Novelli G, Melino G, Lauro R, and Federici M. MicroRNA 217 modulates endothelial cell senescence via silent information regulator 1. Circulation 120: 1524-1532, 2009.

121. Michishita E, McCord RA, Berber E, Kioi M, PadillaNash H, Damian M, Cheung P, Kusumoto R, Kawahara TL, Barrett JC, Chang HY, Bohr VA, Ried T, Gozani O, 
and Chua KF. SIRT6 is a histone H3 lysine 9 deacetylase that modulates telomeric chromatin. Nature 452: 492-496, 2008.

122. Michishita E, McCord RA, Boxer LD, Barber MF, Hong $\mathrm{T}$, Gozani O, and Chua KF. Cell cycle-dependent deacetylation of telomeric histone $\mathrm{H} 3$ lysine $\mathrm{K} 56$ by human SIRT6. Cell Cycle 8: 2664-2666, 2009.

123. Migliaccio E, Giorgio M, Mele S, Pelicci G, Reboldi P, Pandolfi PP, Lanfrancone L, and Pelicci PG. The p66shc adaptor protein controls oxidative stress response and life span in mammals. Nature 402: 309-213, 1999.

124. Ming GF, Tang YJ, Hu K, Chen Y, Huang WH, and Xiao $\mathrm{J}$. Visfatin attenuates the ox-LDL-induced senescence of endothelial progenitor cells by upregulating SIRT1 expression through the PI3K/Akt/ERK pathway. Int $\mathrm{J}$ Mol Med 38: 643-649, 2016.

125. Minor RK, Baur JA, Gomes AP, Ward TM, Csiszar A, Mercken EM, Abdelmohsen K, Shin YK, Canto C, Scheibye-Knudsen M, Krawczyk M, Irusta PM, MartínMontalvo A, Hubbard BP, Zhang Y, Lehrmann E, White AA, Price NL, Swindell WR, Pearson KJ, Becker KG, Bohr VA, Gorospe M, Egan JM, Talan MI, Auwerx J, Westphal CH, Ellis JL, Ungvari Z, Vlasuk GP, Elliott PJ, Sinclair DA, and de Cabo R. SRT1720 improves survival and health span of obese mice. Sci Rep 1: 70, 2011.

126. Miranda MX, van Tits LJ, Lohmann C, Arsiwala T, Winnik S, Tailleux A, Stein S, Gomes AP, Suri V, Ellis JL, Lutz TA, Hottiger MO, Sinclair DA, Auwerx J, Schoonjans K, Staels B, Lüscher TF, and Matter CM. The Sirt1 activator SRT3025 provides atheroprotection in Apoe-1- mice by reducing hepatic Pcsk9 secretion and enhancing Ldlr expression. Eur Heart J 36: 51-59, 2015.

127. Mittal M, Siddiqui MR, Tran K, Reddy SP, and Malik AB. Reactive oxygen species in inflammation and tissue injury. Antioxid Redox Signal 20: 1126-1167, 2014.

128. Mozos I and Luca CT. Crosstalk between oxidative and nitrosative stress and arterial stiffness. Curr Vasc Pharmacol 2017 [Epub ahead of print]; DOI: 10.2174/ 1570161115666170201115428.

129. Nadtochiy SM, Redman E, Rahman I, and Brookes PS. Lysine deacetylation in ischaemic preconditioning: the role of SIRT1. Cardiovasc Res 89: 643-649, 2011.

130. Nadtochiy SM, Yao H, McBurney MW, Gu W, Guarente L, Rahman I, and Brookes PS. SIRT1-mediated acute cardioprotection. Am J Physiol Heart Circ Physiol 301: H1506-H1512, 2011.

131. Napoli C, Balestrieri ML, Sica V, Lerman LO, Crimi E, De Rosa G, Schiano C, Servillo L, and D'Armiento FP. Beneficial effects of low doses of red wine consumption on perturbed shear stress-induced atherogenesis. Heart Vessels 23: 124-133, 2008.

132. Nemoto $\mathrm{S}$ and Finkel T. Redox regulation of forkhead proteins through a p66shc-dependent signaling pathway. Science 295: 2450-2452, 2002.

133. Nisoli E, Tonello C, Cardile A, Cozzi V, Bracale R, Tedesco L, Falcone S, Valerio A, Cantoni O, Clementi E, Moncada S, and Carruba MO. Calorie restriction promotes mitochondrial biogenesis by inducing the expression of eNOS. Science 310: 314-317, 2005.

134. Oka S, Alcendor R, Zhai P, Park JY, Shao D, Cho J, Yamamoto T, Tian B, and Sadoshima J. PPAR $\alpha-$ Sirt 1 complex mediates cardiac hypertrophy and failure through suppression of the ERR transcrip-tional pathway. Cell Metab 14: 598-611, 2011.
135. Orimo M, Minamino T, Miyauchi H, Tateno K, Okada S, Moriya J, and Komuro I. Protective role of SIRT1 in diabetic vascular dysfunction. Arterioscler Thromb Vasc Biol 29: 889-894, 2009.

136. Ota H, Akishita M, Eto M, Iijima K, Kaneki M, and Ouchi Y. Sirt1 modulates premature senescence-like phenotype in human endothelial cells. J Mol Cell Cardiol 43: 571579, 2007.

137. Ota H, Eto M, Kano MR, Ogawa S, Iijima K, Akishita M, and Ouchi Y. Cilostazol inhibits oxidative stress-induced premature senescence via upregulation of Sirt1 in human endothelial cells. Arterioscler Thromb Vasc Biol 28: 1634-1639, 2008.

138. Ou H-C, Chou F-P, Sheen H-M, Lin T-M, Yang C-H, and Huey-Herng Sheu W. Resveratrol, a polyphenolic compound in red wine, protects against oxidized LDL-induced cytotoxicity in endothelial cells. Clin Chim Acta 364: 196-204, 2006.

139. Pan H, Guan D, Liu X, Li J, Wang L, Wu J, Zhou J, Zhang W, Ren R, Zhang W, Li Y, Yang J, Hao Y, Yuan T, Yuan G, Wang H, Ju Z, Mao Z, Li J, Qu J, Tang F, and Liu GH. SIRT6 safeguards human mesenchymal stem cells from oxidative stress by coactivating NRF2. Cell Res 26: 190205, 2016.

140. Pan PW, Feldman JL, Devries MK, Dong A, Edwards $\mathrm{AM}$, and Denu JM. Structure and biochemical functions of SIRT6. J Biol Chem 286: 14575-14587, 2011.

141. Pan W, Yu H, Huang S, and Zhu P. Resveratrol protects against TNF- $\alpha$-induced injury in human umbilical endothelial cells through promoting Sirtuin-1-induced repression of NF-KB and p38 MAPK. PLoS One 11: e0147034, 2016.

142. Paneni F, Volpe M, Lüscher TF, and Cosentino F. SIRT1, p66(Shc), and Set7/9 in vascular hyperglycemic memory: bringing all the strands together. Diabetes 62: 1800-1807, 2013.

143. Panigrahy SK, Bhatt R, and Kumar A. Reactive oxygen species: sources, consequences and targeted therapy in type 2 diabetes. J Drug Target 25: 93-101, 2017.

144. Panth N, Paudel KR, and Parajuli K. Reactive oxygen species: a key hallmark of cardiovascular disease. $A d v$ Med 2016: 9152732, 2016.

145. Paschalaki KE, Starke RD, Hu Y, Mercado N, Margariti A, Gorgoulis VG. Randi AM, and Barnes PJ. Dysfunction of endothelial progenitor cells from smokers and chronic obstructive pulmonary disease patients due to increased DNA damage and senescence. Stem Cells 31: 2813-2826, 2013.

146. Paulin R, Dromparis P, Sutendra G, Gurtu V, Zervopoulos S, Bowers L, Haromy A, Webster L, Provencher S, Bonnet S, and Michelaki ED. Sirtuin 3 deficiency is associated with inhibited mitochondrial function and pulmonary arterial hypertension in rodents and humans. Cell Metab 20: 827-839, 2014.

147. Pinton P, Rimessi A, Marchi S, Orsini F, Migliaccio E, Giorgio M, Contursi C, Minucci S, Mantovani F, Wieckowski MR, Del Sal G, Pelicci PG, and Rizzuto R. Protein kinase $\mathrm{C}$ beta and prolyl isomerase 1 regulate mitochondrial effects of the life-span determinant p66Shc. Science 315: 659-663, 2007.

148. Prola A, Silva JP, Guilbert A, Lecru L, Piquereau J, Ribeiro M, Mateo P, Gressette M, Fortin D, Boursier C, Gallerne C, Caillard A, Samuel JL, François H, Sinclair DA, Eid P, Ventura-Clapier R, Garnier A, and Lemaire C. 
SIRT1 protects the heart from ER stress-induced cell death through eIF2 $\alpha$ deacetylation. Cell Death Differ 24: 343-356, 2017.

149. Qian L, Ma L, Wu G, Yu Q, Lin H, Ying Q, Wen D, and Gao C. G004, a synthetic sulfonylurea compound, exerts anti-atherosclerosis effects by targeting SIRT1 in ApoE-/mice. Vasc Pharmacol 89: 49-57, 2017.

150. Rajendrasozhan S, Yang SR, Kinnula VL, and Rahman I. SIRT1, an antiinflammatory and antiaging protein, is decreased in lungs of patients with chronic obstructive pulmonary disease. Am J Respir Crit Care Med 177: 861870, 2008.

151. Rota M, LeCapitaine N, Hosoda T, Boni A, De Angelis A, Padin-Iruegas ME, Esposito G, Vitale S, Urbanek K, Casarsa C, Giorgio M, Lüscher TF, Pelicci PG, Anversa P, Leri A, and Kajstura J. Diabetes promotes cardiac stem cell aging and heart failure, which are prevented by deletion of the p66she gene. Circ Res 99: 42-52, 2006.

152. Sanchez-Fidalgo S, Villegas I, Sanchez-Hidalgo M, and de la Lastra CA. Sirtuin modulators: mechanisms and potential clinical implications. Curr Med Chem 19: 24142441, 2012.

153. Santilli F, D'Ardes D, and Davi G. Oxidative stress in chronic vascular disease: from prediction to prevention. Vasc Pharmacol 74: 23-37, 2015.

154. Schwer B, Schumacher B, Lombard DB, Xiao C, Kurtev MV, Gao J, Schneider JI, Chai H, Bronson RT, Tsai LH, Deng CX, and Alt FW. Neural sirtuin6 (Sirt6) ablation attenuates somatic growth and causes obesity. Proc Natl Acad Sci U S A 107: 21790-21794, 2010.

155. Sena CM, Pereira AM, and Seica R. Endothelial dysfunction-a major mediator of diabetic vascular disease. Biochim Biophys Acta 1832: 2216-2231, 2013.

156. Servillo L, Castaldo D, Casale R, D’Onofrio N, Giovane A, Cautela D, and Balestrieri ML. An uncommon redox behavior sheds light on the cellular antioxidant properties of ergothioneine. Free Radic Biol Med 79: 228-236, 2015.

157. Servillo L, D'Onofrio N, and Balestrieri ML. Ergothioneine antioxidant function: from chemistry to cardiovascular therapeutic potential. J Cardiovasc Pharmacol 69: 183-191, 2017.

158. Servillo L, D’Onofrio N, Longobardi L, Sirangelo I, Giovane A, Cautela D, Castaldo D, Giordano A, and Balestrieri ML. Stachydrine ameliorates high-glucose induced endothelial cell senescence and SIRT1 downregulation. J Cell Biochem 114: 2522-2530, 2013.

159. Simeoni F, Tasselli L, Tanaka S, Villanova L, Hayashi M, Kubota K, Isono F, Garcia BA, Michishita-Kioi E, and Chua KF. Proteomic analysis of the SIRT6 interactome: novel links to genome maintenance and cellular stress signaling. Sci Rep 3: 3085, 2013.

160. Sociali G, Magnone M, Ravera S, Damonte P, Vigliarolo T, Von Holtey M, Vellone VG, Millo E, Caffa I, Cea M, Parenti MD, Del Rio A, Murone M, Mostoslavsky R, Grozio A, Nencioni A, and Bruzzone S. Pharmacological Sirt6 inhibition improves glucose tolerance in a type 2 diabetes mouse model. FASEB J pii: fj.201601294R, 2017.

161. Sorci-Thomas MG and Thomas MJ. Microdomains, inflammation, and atherosclerosis. Circ Res 118: 679-691, 2016.

162. Stein S, Lohmann C, Schäfer N, Hofmann J, Rohrer L, Besler C, Rothgiesser KM, Becher B, Hottiger MO, Borén J, McBurney MW, Landmesser U, Lüscher TF, and Matter
CM. SIRT1 decreases Lox-1-mediated foam cell formation in atherogenesis. Eur Heart J 31: 2301-2309, 2010.

163. Stein S, Schäfer N, Breitenstein A, Besler C, Winnik S, Lohmann C, Heinrich K, Brokopp CE, Handschin C, Landmesser U, Tanner FC, Lüscher TF, and Matter CM. SIRT1 reduces endothelial activation without affecting vascular function in ApoE-/- mice. Aging (Albany NY) 2: 353-360, 2010.

164. Sulaiman M, Matta MJ, Sunderesan NR, Gupta MP, Periasamy M, and Gupta M. Resveratrol, an activator of SIRT1, upregulates sarcoplasmic calcium ATPase and improves cardiac function in diabetic cardiomyopathy. Am J Physiol Heart Circ Physiol 298: H833-H843, 2010.

165. Sundaresan NR, Pillai VB, Wolfgeher D, Samant S, Vasudevan P, Parekh V, Raghuraman H, Cunningham JM, Gupta M, and Gupta MP. The deacetylase SIRT1 promotes membrane localization and activation of Akt and PDK1 during tumorigenesis and cardiac hypertrophy. Sci Signal 4: ra46, 2011.

166. Sundaresan NR, Vasudevan P, Zhong L, Kim G, Samant S, Parekh V, Pillai VB, Ravindra PV, Gupta M, Jeevanandam V, Cunningham JM, Deng CX, Lombard DB, Mostoslavsky R, and Gupta MP. The sirtuin SIRT6 blocks IGF-Akt signaling and development of cardiac hypertrophy by targeting c-Jun. Nat Med 18: 1643-1650, 2012.

167. Tabatabaei-Malazy O, Fakhrzadeh H, Sharifi F, Mirarefin M, Arzaghi SM, Badamchizadeh Z, Alizadeh Khoee M, and Larijani B. Effect of metabolic control on oxidative stress, subclinical atherosclerosis and peripheral artery disease in diabetic patients. J Diabetes Metab Disord 14: 84,2015

168. Tan M, Tang C, Zhang Y, Cheng Y, Cai L, Chen X, Gao Y, Deng Y, and Pan M. SIRT1/PGC-1alpha signaling protects hepatocytes against mitochondrial oxidative stress induced by bile acids. Free Radic Res 49: 935-945, 2015.

169. Tanno M, Sakamoto J, Miura T, Shimamoto K, and Horio Y. Nucleo cytoplasmic shuttling of the NAD+-dependent histone deacetylase SIRT1. J Biol Chem 282: 6823-6832, 2007.

170. Tao R, Xiong X, Depinho RA, Deng CX, and Dong XC. Hepatic SREBP-2 and cholesterol biosynthesis are regulated by FoxO3 and Sirt6. J Lipid Res 54: 2745-2753, 2013.

171. Tasselli L, Xi Y, Zheng W, Tennen RI, Odrowaz Z, Simeoni F, Li W, and Chua KF. SIRT6 deacetylates H3 K18ac at pericentric chromatin to prevent mitotic errors and cellular senescence. Nat Struct Mol Biol 23: 434-440, 2016.

172. Tasselli L, Zheng W, and Chua KF. SIRT6: novel mechanisms and links to aging and disease. Trends Endocrinol Metab 28: 168-185, 2017.

173. Tennen RI, Bua DJ, Wright WE, and Chua KF. SIRT6 is required for maintenance of telomere position effect in human cells. Nat Commun 2: 433, 2011.

174. Thandavarayan RA, Garikipati VN, Joladarashi D, Suresh Babu S, Jeyabal P, Verma SK, Mackie AR, Khan M, Arumugam S, Watanabe K, Kishore R, and Krishnamurthy P. Sirtuin-6 deficiency exacerbates diabetesinduced impairment of wound healing. Exp Dermatol 24: 773-877, 2015.

175. Thompson AM, Wagner R, and Rzucidlo EM. Age-related loss of SirT1 expression results in dysregulated human vascular smooth muscle cell function. Am J Physiol Heart Circ Physiol 307: H533-H541, 2014.

176. Tian K, Liu Z, Wang J, Xu S, You T, and Liu P. Sirtuin-6 inhibits cardiac fibroblasts differentiation into myofibroblasts 
via inactivation of nuclear factor $\kappa \mathrm{B}$ signaling. Transl Res 165: 374-386, 2015.

177. Trinei M, Migliaccio E, Bernardi P, Paolucci F, Pelicci P, and Giorgio M. p66Shc, mitochondria, and the generation of reactive oxygen species. Methods Enzymol 528: 99110, 2013.

178. Ungvari Z, Bailey-Downs L, Gautam T, Jimenez R, Losonczy G, Zhang C, Ballabh P, Recchia FA, Wilkerson DC, Sonntag WE, Pearson K, de Cabo R, and Csiszar A. Adaptive induction of NF-E2-related factor-2-driven antioxidant genes in endothelial cells in response to hyperglycemia. Am J Physiol Heart Circ Physiol 300: H1133H1140, 2011.

179. Ungvari Z, Labinskyy N, Mukhopadhyay P, Pinto JT, Bagi Z, Ballabh P, Zhang C, Pacher P, and Csiszar A. Resveratrol attenuates mitochondrial oxidative stress in coronary arterial endothelial cells. Am J Physiol Heart Circ Physiol 297: H1876-H1881, 2009.

180. Ungvari Z, Parrado-Fernandez C, Csiszar A, and de Cabo $\mathrm{R}$. Mechanisms underlying caloric restriction and lifespan regulation: implications for vascular aging. Circ Res 102: 519-528, 2008.

181. Van Meter M, Kashyap M, Rezazadeh S, Geneva AJ, Morello TD, Seluanov A, and Gorbunova V. SIRT6 represses LINE1 retrotransposons by ribosylating KAP1 but this repression fails with stress and age. Nat Commun 5: 5011, 2014.

182. Van Meter M, Simon M, Tombline G, May A, Morello TD, Hubbard BP, Bredbenner K, Park R, Sinclair DA, Bohr VA, Gorbunova V, and Seluanov A. JNK phosphorylates SIRT6 to stimulate DNA double-strand break repair in response to oxidative stress by recruiting PARP1 to DNA Breaks. Cell Rep 16: 2641-2650, 2016.

183. Vasko R, Xavier S, Chen J, Lin CH, Ratliff B, Rabadi M, Maizel J, Tanokuchi R, Zhang F, Cao J, and Goligorsky MS. Endothelial sirtuin 1 deficiency perpetrates nephrosclerosis through downregulation of matrix metalloproteinase-14: relevance to fibrosis of vascular senescence. $\mathrm{J} \mathrm{Am} \mathrm{Soc} \mathrm{Ne-}$ phrol 25: 276-291, 2014.

184. Venkatasubramanian S, Noh RM, Daga S, Langrish JP, Joshi NV, Mills NL, Hoffmann E, Jacobson EW, Vlasuk GP, Waterhouse BR, Lang NN, and Newby DE. Cardiovascular effects of a novel SIRT1 activator, SRT2104, in otherwise healthy cigarette smokers. J Am Heart Assoc 2: e000042, 2013.

185. Verdin E. The many faces of sirtuins: coupling of NAD metabolism, sirtuins and lifespan. Nat Med 20: 25-27, 2014.

186. Vikram A, Lewarchik CM, Yoon JY, Naqvi A, Kumar S, Morgan GM, Jacobs JS, Li Q, Kim YR, Kassan M, Liu J, Gabani M, Kumar A, Mehdi H, Zhu X, Guan X, Kutschke W, Zhang X, Boudreau RL, Dai S, Matasic DS, Jung SB, Margulies KB, Kumar V, Bachschmid MM, London B, and Irani K. Sirtuin 1 regulates cardiac electrical activity by deacetylating the cardiac sodium channel. Nat Med 23: 361-367, 2017.

187. Vinciguerra M, Santini MP, Martinez C, Pazienza V, Claycomb WC, Giuliani A, and Rosenthal N. mIGF-1/ JNK1/SirT1 signaling confers protection against oxidative stress in the heart. Aging Cell 11: 139-149, 2012.

188. Vitiello M, Zullo A, Servillo L, Mancini FP, Borriello A, Giovane A, Della Ragione F, D'Onofrio N, and Balestrieri ML. Multiple pathways of SIRT6 at the crossroads in the control of longevity, cancer, and cardiovascular diseases. Ageing Res Rev 35: 301-311, 2017.
189. Wan YZ, Gao P, Zhou S, Zhang ZQ, Hao DL, Lian LS, Li YJ, Chen HZ, and Liu DP. SIRT1-mediated epigenetic downregulation of plasminogen activator inhibitor-1 prevents vascular endothelial replicative senescence. Aging Cell 13: 890-899, 2014.

190. Wang B, Yang Q, Sun YY, Xing YF, Wang YB, Lu XT, Bai WW, Liu XQ, and Zhao YX. Resveratrol-enhanced autophagic flux ameliorates myocardial oxidative stress injury in diabetic mice. J Cell Mol Med 18: 1599-1611, 2014.

191. Wang WW, Zeng Y, Wu B, Deiters A, and Liu WR. A chemical biology approach to reveal Sirt6-targeted histone H3 sites in nucleosomes. ACS Chem Biol 11: 1973-1981, 2016.

192. Wang XX, Wang XL, Tong MM, Gan L, Chen H, Wu SS, Chen JX, Li, RL, Wu Y, Zhang HY, Zhu Y, Li YX, He JH, Wang M, and Jiang W. SIRT6 protects cardiomyocytes against ischemia/reperfusion injury by augmenting FoxO $3 \alpha$-dependent antioxidant defense mechanisms. $\mathrm{Ba}$ sic Res Cardiol 111: 13, 2016.

193. Wen L, Chen Z, Zhang F, Cui X, Sun W, Geary GG, Wang Y, Johnson DA, Zhu Y, Chien S, and Shyy JY. Ca2+l calmodulin-dependent protein kinase kinase beta phosphorylation of Sirtuin 1 in endothelium is atheroprotective. Proc Natl Acad Sci U S A 110: E2420-E2427, 2013.

194. Wils J, Favre J, and Bellien J. Modulating putative endothelial progenitor cells for the treatment of endothelial dysfunction and cardiovascular complications in diabetes. Pharmacol Ther 170: 98-115, 2017.

195. Winnik S, Auwerx J, Sinclair DA, and Matter CM. Protective effects of sirtuins in cardiovascular diseases: from bench to bedside. Eur Heart J 36: 3404-3412, 2015.

196. Wu J, Xia S, Kalionis B, Wan W, and Sun T. The role of oxidative stress and inflammation in cardiovascular aging. Biomed Res Int 2014: 615312, 2014.

197. Xia J, Wu X, Yang Y, Zhao Y, Fang M, Xie W, Wang H, and Xu Y. SIRT1 deacetylates RFX5 and antagonizes repression of collagen type I (COL1A2) transcription in smooth muscle cells. Biochem Biophys Res Commun 428: 264-270, 2012.

198. Xiong X, Wang G, Tao R, Wu P, Kono T, Li K, Ding WX, Tong X, Tersey SA, Harris RA, Mirmira RG, EvansMolina C, and Dong XC. Sirtuin 6 regulates glucosestimulated insulin secretion in mouse pancreatic beta cells. Diabetologia 59: 151-160, 2015.

199. Xu S, Bai P, and Jin ZG. Sirtuins in cardiovascular health and diseases. Trends Endocrinol Metab 27: 677-678, 2016.

200. Xu S, Yin M, Koroleva M, Mastrangelo MA, Zhang W, Bai P, Little PJ, and Jin ZG. SIRT6 protects against endothelial dysfunction and atherosclerosis in mice. Aging (Albany NY) 8: 1064-1082, 2016.

201. Xu W, Deng YY, Yang L, Zhao S, Liu J, Zhao Z, Wang L, Maharjan P, Gao S, Tian Y, Zhuo X, Zhao Y, Zhou J, Yuan $\mathrm{Z}$, and $\mathrm{Wu} \mathrm{Y}$. Metformin ameliorates the proinflammatory state in patients with carotid artery atherosclerosis through sirtuin 1 induction. Transl Res 166: 451-458, 2015.

202. Yamamoto T, Byun J, Zhai P, Ikeda Y, Oka S, and Sadoshima J. Nicotinamide mononucleotide, an intermediate of NAD+ synthesis, protects the heart from ischemia and reperfusion. PLoS One 9: e98972, 2014.

203. Yan H, Jihong Y, Feng Z, Xiaomei X, Xiaohan Z, Guangzhi W, Zhenhai M, Dongyan G, Xiaochi M, Qing F, Kexin L, and Xiaofeng T. Sirtuin 1-mediated inhibition of p66shc expression alleviates liver ischemia/reperfusion injury. Crit Care Med 42: e373-e381, 2014. 
204. Yang L, Zhang J, Yan C, Zhou J, Lin R, Lin Q, Wang W, Zhang K, Yang G, Bian X, and Zeng A. SIRT1 regulates CD40 expression induced by TNF alpha via NF-kB pathway in endothelial cells. Cell Physiol Biochem 30: 1287-1298, 2012.

205. Yang Y, Fu W, Chen J, Olashaw N, Zhang X, Nicosia SV, Bhalla K, and Bai W. SIRT1 sumoylation regulates its deacetylase activity and cellular response to genotoxic stress. Nat Cell Biol 9: 1253-1262, 2007.

206. Yao H, Chung S, Hwang JW, Rajendrasozhan S, Sundar IK, Dean DA, McBurney MW, Guarente, L, Gu W, Ronty M, Kinnula VL, and Rahman I. SIRT1 protects against emphysema via FOXO3- mediated reduction of premature senescence in mice. J Clin Invest 122: 2032-2045, 2012.

207. Yeung F, Hoberg JE, Ramsey CS, Keller MD, Jones DR, Frye RA, and Mayo MW. Modulation of NF-kappaBdependent transcription and cell survival by the SIRT1 deacetylase. EMBO J 23: 2369-2380, 2004.

208. Yoshizaki T, Schenk S, Imamura T, Babendure JL, Sonoda N, Bae EJ, Oh DY, Lu M, Milne JC, Westphal C, Bandyopadhyay G, and Olefsky JM. SIRT1 inhibits inflammatory pathways in macrophages and modulates insulin sensitivity. Am J Physiol Endocrinol Metab 298: E419-E428, 2010.

209. Yu SS, Cai Y, Ye JT, Pi RB, Chen SR, Liu PQ, Shen XY, and Ji Y. Sirtuin 6 protects cardiomyocytes from hypertrophy in vitro via inhibition of NF- $\kappa \mathrm{B}$-dependent transcriptional activity. Br J Pharmacol 168: 117-128, 2013.

210. Yuan Q, Chen L, Xiang DX, Li YJ, and Hu CP. Effect of resveratrol derivative BTM-0512 on high glucose-induced dysfunction of endothelial cells: role of SIRT1. Can J Physiol Pharmacol 89: 713-722, 2011.

211. Zhang N, Li Z, Mu W, Li L, Liang Y, Lu M, Wang Z, Qiu $\mathrm{Y}$, and Wang Z. Calorie restriction-induced SIRT6 activation delays aging by suppressing NF- $\kappa \mathrm{B}$ signaling. Cell Cycle 15: 1009-1018, 2016.

212. Zhang P, Li Y, Du Y, Li G, Wang L, and Zhou F. Resveratrol ameliorated vascular calcification by regulating Sirt-1 and Nrf2. Transplant Proc 48: 3378-3386, 2016.

213. Zhang P, Tu B, Wang H, Cao Z, Tang M, Zhang C, Gu B, Li Z, Wang L, Yang Y, Zhao Y, Wang H, Luo J, Deng CX, Gao B, Roeder RG, and Zhu WG. Tumor suppressor p53 cooperates with SIRT6 to regulate gluconeogenesis by promoting FoxO1 nuclear exclusion. Proc Natl Acad Sci U S A 111: 10684-10689, 2014.

214. Zhang QJ, Wang Z, Chen HZ, Zhou S, Zheng W, Liu G, Wei YS, Cai H, Liu DP, and Liang CC. Endotheliumspecific overexpression of class III deacetylase SIRT1 decreases atherosclerosis in apolipoprotein E-deficient mice. Cardiovasc Res 80: 191-199, 2008.

215. Zhang X, Li W, Shen P, Feng X, Yue Z, Lu J, You J, Li J, Gao H, Fang S, Li Z, and Liu P. STAT3 suppression is involved in the protective effect of SIRT6 against cardiomyocyte hypertrophy. J Cardiovasc Pharmacol 68: 204214, 2016.

216. Zhang Y, Cao X, Zhu W, Liu Z, Liu H, Zhou Y, Cao Y, Liu C, and Xie Y. Resveratrol enhances autophagic flux and promotes ox-LDL degradation in HUVECs via upregulation of SIRT1. Oxid Med Cell Longev 2016: 7589813, 2016.

217. Zhang Y, Sun J, Yu X, Shi L, Du W, Hu L, Liu C, and Cao Y. SIRT1 regulates accumulation of oxidized LDL in HUVEC via the autophagy-lysosomal pathway. Prostaglandins Other Lipid Mediat 122: 37-44, 2016.
218. Zhang ZQ, Ren SC, Tan Y, Li ZZ, Tang X, Wang TT, Hao DL, Zhao X, Chen HZ, and Liu DP. Epigenetic regulation of NKG2D ligands is involved in exacerbated atherosclerosis development in Sirt6 heterozygous mice. Sci Rep 6: 23912, 2016.

219. Zhao G, Wang H, Xu C, Wang P, Chen J, Wang P, Sun Z, Su Y, Wang Z, Han L, and Tong T. SIRT6 delays cellular senescence by promoting p27Kip1 ubiquitin-proteasome degradation. Aging (Albany NY) 8: 2308-2323, 2016.

220. Zhao LR, Du YJ, Chen L, Liu ZG, Pan YH, Liu JF, and Liu B. Quercetin protects against high glucose-induced damage in bone marrow-derived endothelial progenitor cells. Int J Mol Med 34: 1025-1031, 2014.

221. Zhou S, Chen HZ, Wan YZ, Zhang QJ, Wei YS, Huang S, Liu JJ, Lu YB, Zhang ZQ, Yang RF, Zhang R, Cai H, Liu DP, and Liang CC. Repression of P66Shc expression by SIRT1 contributes to the prevention of hyperglycemiainduced endothelial dysfunction. Circ Res 109: 639-648, 2011.

Address correspondence to: Prof. Maria Luisa Balestrieri Department of Biochemistry, Biophysics and General Pathology School of Medicine and Surgery Università degli Studi della Campania "Luigi Vanvitelli",

Via L. De Crecchio 7 Naples 80138 Italy

E-mail: marialuisa.balestrieri@unicampania.it

Date of first submission to ARS Central, May 18, 2017; date of acceptance, May 24, 2017.

\begin{tabular}{|c|}
\hline 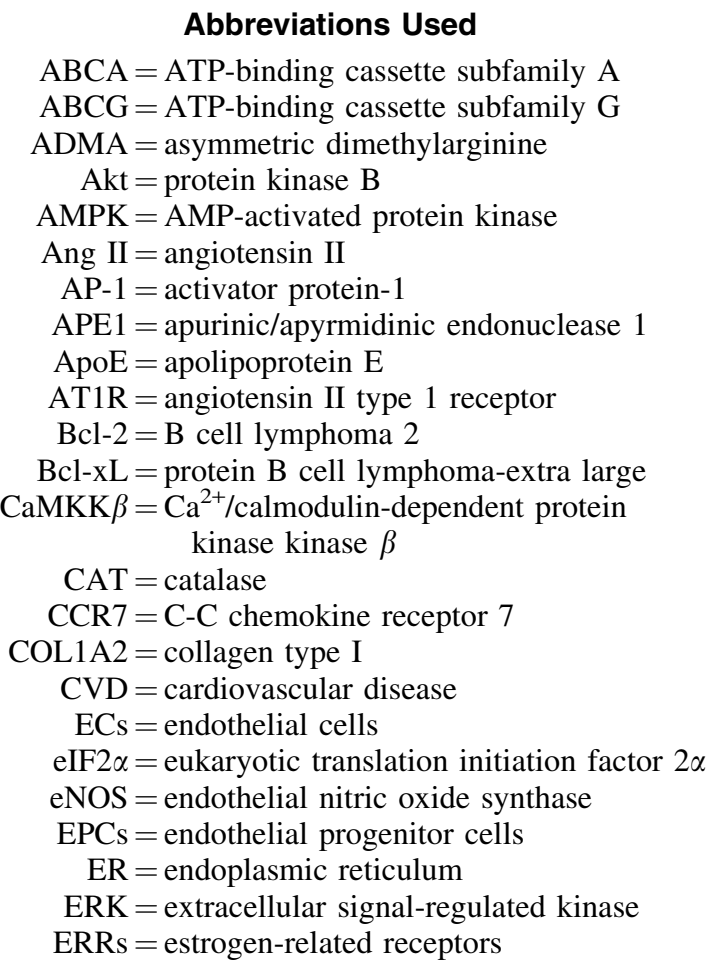 \\
\hline
\end{tabular}




\section{Abbreviations Used (Cont.)}

$\operatorname{ER} \beta=$ estrogen receptor $\beta$

$\mathrm{FOXO}=$ forkhead box $\mathrm{O}$

$\mathrm{GH}=$ growth hormone

$\mathrm{GPx}=$ glutathione peroxidase

$\mathrm{H} 3=$ histone type 3

$\mathrm{I} / \mathrm{R}=$ ischemia-reperfusion

ICAM-1 = intercellular adhesion molecule-1

IGF $=$ insulin-like growth factor

$\mathrm{IL}=$ interleukin

iNOS $=$ inducible nitric oxide synthase

$\mathrm{JNK}=\mathrm{c}$-Jun $\mathrm{N}$-terminal kinase

LINE-1 = long interspersed element-1

$\mathrm{LKB} 1=$ liver kinase $\mathrm{B} 1$

Lox-1 = lectin-like oxLDL receptor 1

$\mathrm{LXR}=$ liver $\mathrm{X}$-receptor

Lys $=$ lysine

MCP-1 = monocyte chemotactic protein-1 $\mathrm{miR}=$ microRNA

MMP-9 = matrix metalloproteinase-9

$\mathrm{MnSOD}=$ manganese superoxide dismutase

mRNA $=$ messenger ribonucleic acid

$\mathrm{NAD}^{+}=$nicotinamide adenine dinucleotide

$\mathrm{NADPH}=$ nicotinamide adenine dinucleotide phosphate

NAMPT $=$ nicotinamide phosphoribosyltransferase

NBS-1 = Nijmegen breakage syndrome-1

$\mathrm{NF}-\kappa \mathrm{B}=$ nuclear factor-kappa $\mathrm{B}$

$\mathrm{NKG} 2 \mathrm{D}=$ natural-killer group 2 member $\mathrm{D}$

Nmnat2 = nicotinamide mononucleotide adenylyl transferase 2

$\mathrm{NO}=$ nitric oxide

$\mathrm{NRF} 1=$ nuclear respiratory factor 1

$\mathrm{Nrf} 2=$ nuclear factor erythroid 2-related factor 2
oxLDL $=$ oxidized low-density lipoproteins

PAI-1 = plasminogen activator inhibitor type 1

PARP1 $=$ poly-(ADP-ribose) polymerase 1

$\mathrm{PCAF}=\mathrm{p} 300 / \mathrm{CBP}-$ associated factor

PCSK9 $=$ proprotein convertase subtilisin/kexin type 9

PDK $1=$ pyruvate dehydrogenase kinase 1

PGC- $1 \alpha=$ proliferator-activated receptor $\gamma$ coactivator- $1 \alpha$

$\mathrm{PH}=$ pleckstrin homology

PIP3 = phosphatidylinositol $(3,4,5)-$ trisphosphate

$\mathrm{PPAR}=$ peroxisome proliferator-activated receptor coactivator

PRMT1 = protein arginine methyl transferase-1

Ref- $1=$ redox factor- 1

RFX5 = regulatory factor for X-box

ROS $=$ reactive oxygen species

Ser $=$ serine

SERCA2a $=$ sarcoplasmic calcium ATPase

SIRT $=$ sirtuin

$\mathrm{SREBP}=$ sterol regulatory element-binding protein

STACs $=$ sirtuin-activating compounds

STAT3 $=$ signal transducer and activator of transcription 3

$\mathrm{TG}=$ triglycerides

TIMP3 $=$ tissue inhibitor of metalloproteinase 3

TNFSF4 $=$ tumor necrosis factor superfamily member 4

TNF- $\alpha=$ tumor necrosis factor- $\alpha$

$\operatorname{Trx} 1=$ thioredoxin -1

VCAM-1 = vascular cell adhesion molecule-1

VSMCs $=$ vascular smooth muscle cells

$\mathrm{XO}=$ xanthine oxidase 